\title{
Efficacy and Safety of Rapid-Acting Insulin Analogs in Special Populations with Type 1 Diabetes or Gestational Diabetes: Systematic Review and Meta-Analysis
}

\author{
Kirsten Nørgaard · Nithya Sukumar · Snorri B. Rafnsson · Ponnusamy Saravanan (D)
}

Received: February 6, 2018/Published online: April 5, 2018

(c) The Author(s) 2018

\section{ABSTRACT}

Introduction: To assess the efficacy and safety of three available rapid-acting insulin analogs (insulins lispro, aspart and glulisine, respectively) in pregnant women, children/adolescents and people using continuous subcutaneous insulin infusion (CSII) with type 1 diabetes.

Methods: PubMed, EMBASE and Cochrane Reviews were searched electronically, and their bibliographies examined to identify

Enhanced content To view enhanced content for this article go to https://doi.org/10.6084/m9.figshare. 5982169.

Electronic supplementary material The online version of this article (https://doi.org/10.1007/s13300018-0411-7) contains supplementary material, which is available to authorized users.

\section{K. Nørgaard}

Department of Endocrinology, Copenhagen

University Hospital Hvidovre, Kettegård Allé 30,

2650 Hvidovre, Denmark

\section{K. Nørgaard}

Steno Diabetes Center Copenhagen, Niels

Steensensvej 2, 2820 Gentofte, Denmark

N. Sukumar · P. Saravanan $(\bowtie)$

Diabetes, Endocrinology and Metabolism, Division of Health Sciences, Warwick Medical School, University of Warwick, Coventry CV4 7AL, UK e-mail: p.saravanan@warwick.ac.uk suitable studies for review and inclusion in a meta-analysis. Eligible studies were randomized controlled trials that reported data on relevant clinical outcomes. A different reviewer abstracted data for each of the three subpopulations, and one reviewer abstracted data for all three. Any differences were resolved by consensus or by consulting a fourth reviewer.

Results: In people on CSII, rapid-acting insulin analogs lowered postprandial plasma glucose post-breakfast to a greater extent than did regular human insulin (RHI) (mean difference: $-1.63 \mathrm{mmol} / \mathrm{L} \quad[95 \%$ confidence interval $-1.71 ;-1.54])$, with a comparable risk of hypoglycemia and a trend for lower glycated hemoglobin. In the pediatric population, glycemic control was similar with rapid-acting insulin analogs and RHI, with no safety concerns. Meta-analysis indicated severe hypoglycemic events were comparable for rapid-

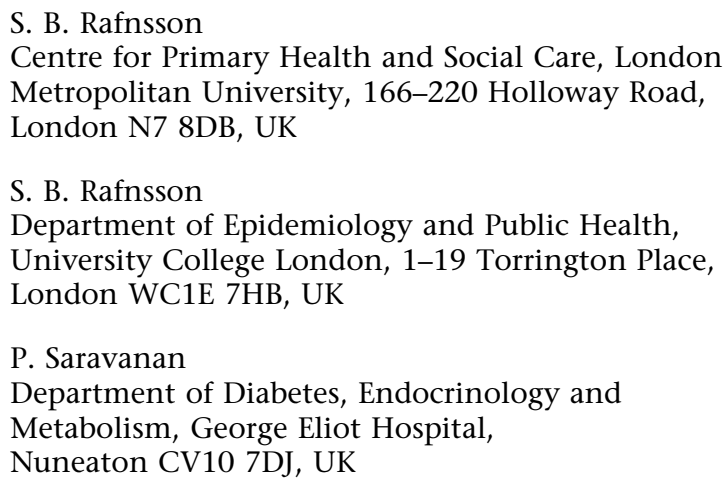


acting insulin analogs versus RHI (risk difference: 0.00 [95\% confidence interval - 0.01; 0.01]). In the pregnancy group, insulin lispro and insulin aspart were safe and effective for both mother and fetus, with glycemic control being at least as good as with RHI. There were no data on insulin glulisine during pregnancy. Conclusion: Rapid-acting insulin analogs appear generally safe and effective in these special populations; however, additional trials would be helpful.

Funding: Novo Nordisk A/S.

Keywords: CSII; Pediatrics; Pregnancy; Rapidacting insulin analogs; Type 1 diabetes

\section{INTRODUCTION}

Many people with type 1 diabetes (T1D) receive insulin therapy [1]. Rapid-acting insulins are typically used to control postprandial plasma glucose (PPG) excursions, whereas long-acting basal insulins are used to control fasting glucose. Rapid-acting insulins are used as part of a basal-bolus injection regimen as well as for continuous subcutaneous insulin infusion (CSII). Three rapid-acting insulin analogs (RAIAs) are currently available in the USA and Europe: insulin lispro (Humalog ${ }^{\circledR}$; Eli Lilly, Indianapolis, IN, USA), insulin aspart (Novolog $^{\circledR}$ in the USA and NovoRapid ${ }^{\circledR}$ in the EU; Novo Nordisk, Bagsværd, Denmark) and insulin glulisine (Apidra $^{\circledR}$; Sanofi Aventis, Bridgewater, NJ, USA). All three of these RAIAs are also approved for the pediatric T1D patient population, although the ages on the product inserts for which there are data vary by product as well as by country (e.g. USA: insulin lispro, children $\geq 3$ years of age; insulin aspart, $\geq 2$ years; insulin glulisine, $\geq 4$ years [2-4]; EU: insulin lispro, age not specified; insulin aspart, $\geq 1$ years; insulin glulisine, $\geq 6$ years) [5-7]. In addition, despite the concerns in some countries, the use of RAIAs is very high in T1D patients in general and is almost 100\% among those patients using CSII [8].

The three insulin analogs lispro, aspart and glulisine differ in how their molecular structure has been modified from human insulin [9] and in the chemical composition of their formulations [10], but their pharmacokinetic (PK) and pharmacodynamic (PD) profiles are similar (Electronic Supplementary Material [ESM] Table S1). A large body of clinical studies indicates that these three RAIAs have similar efficacy and safety [11] and that they are preferred over regular human insulin (RHI) for use in adults with T1D due to their lower risk of hypoglycemia [12].

However, certain subgroups of patients with T1D (e.g. children and adolescents, pregnant women and people using CSII) are typically excluded from trials conducted for regulatory approval to ensure a more homogeneous group of patients.

A consequence of excluding these patients from regulatory trials is that there is some uncertainty about the clinical profile of RAIAs in patients who may have unique metabolic, developmental, cognitive or behavioral issues that materially affect the suitability of any medication. With RAIAs in widespread clinical use, it is timely to examine the available evidence for their performance in special populations. Thus, we performed a systematic review and meta-analysis of published data (PROSPERO registration \#CRD42016043006).

\section{METHODS}

\section{Sources of Data and Search Criteria}

The search terms "insulin lispro" (MeSH Terms) OR "insulin" (All Fields) AND "lispro" (All Fields) OR "insulin lispro" (All Fields) OR "lispro" (All Fields) OR aspart (All Fields) OR glulisine (All Fields) were used to search the PubMed, EMBASE and the Cochrane Reviews databases electronically on 1 June 2016 to identify records for further examination. The titles and abstracts (and, when necessary, full papers) were then screened to identify papers potentially reporting relevant in vivo data on safety or efficacy in randomized controlled trials (RCTs) involving one of three special populations (children and adolescents with T1D; pregnant women with pre-gestational T1D or gestational diabetes [GDM]; people with T1D using CSII). We did 
not set a date range and therefore included any study published up to the date of the search. Reference lists of retrieved publications and targeted review articles of RAIAs were also searched to identify additional records that might be provisionally relevant.

\section{Selection of Studies and Eligibility Criteria}

Records identified as provisionally relevant were then further examined for eligibility to verify that they were indeed RCTs, either blinded or open-label and of parallel or crossover design, in one of the target special populations and that they reported data on one of the identified clinical outcomes of interest. Eligibility for the three study populations was as follows: for the pregnancy population, women with either pregestational T1D or GDM; for the pediatric population, children or adolescents aged $<18$ years with T1D; for the CSII population, people with T1D of any age using an insulin pump.

The criterion for the treatment in eligible studies was the administration of one of the three RAIAs compared with either RHI or each other; trials in which the effect of the RAIA could not be isolated (as in basal-bolus trials in which different basal insulins were used in each arm) were excluded. We did not pre-specify a minimum duration for the studies, although very short-term (e.g. 1- to 2-day meal tests designed to study PK/PD) were excluded. Outcome measures of interest included glycated hemoglobin (HbA1c), fasting blood glucose (FBG) or plasma glucose, PPG after any or all of the three main meals, hypoglycemia, hyperglycemia, diabetic ketoacidosis and/or pump/catheter occlusion and, for pregnancy, fetal outcomes.

\section{Data Extraction}

A standardized data abstraction form was adapted for use in this systematic review. A different reviewer abstracted data for each of the three subpopulations (KN, NS, SR) using the inclusion and exclusion criteria, and one reviewer abstracted data for all three of the subpopulations. Any differences were resolved by consensus or, if necessary, by consulting a fourth reviewer (PS) not involved in the original data abstraction process for that population. All reviewers are qualified at a post-doctorate level.

\section{Data Synthesis and Statistical Analysis}

For each of the three populations, whenever possible, we extracted data on glycemic control (HbA1c at baseline and end of trial; percentage of patients achieving $\mathrm{HbA} 1 \mathrm{c}$ target[s] as specified in individual trials; 7- or 8-point selfmeasured blood glucose [SMBG]); and safety endpoints (e.g. severe, nocturnal, overall hypoglycemia; hyperglycemia/ketosis; fetal outcomes). For completeness, we also extracted other secondary endpoints if available. Each of the retrieved studies was assessed for study quality, including sample size, reporting of methods, reporting of results and risk of bias. Finally, using this information, we graded each study according to the following scale $(-,+$, $++)$, with - indicating poor quality, + indicating average quality and ++ indicating good quality.

All authors reviewed the available outcomes data for each eligible study and decided which studies had efficacy and/or safety data that would be suitable for data combination and meta-analysis within each of the three special populations. Suitability was determined by authors' assessment of comparability of the outcomes assessed.

Meta-analysis was conducted using Review Manager 5 (RevMan 5.3 [http://community. cochrane.org/tools/review-production-tools/rev man-5]) software for Cochrane Reviews. Two different outcome measures were used for the safety variables in the meta-analysis (namely risk difference for severe and any hypoglycemic episodes per month) and three outcome measures for the efficacy variables (namely mean difference in fasting and postprandial blood glucose $[\mathrm{BG}]$ and in HbA1c). All models were run as random-effects models. Statistical heterogeneity was calculated by using the $I^{2}$ statistic, and publication bias was assessed by using a funnel plot and the Egger's test. 


\section{Compliance with Ethics Statement}

This article is based on previously conducted studies and does not involve any new studies of human or animal subjects performed by any of the authors.

\section{RESULTS}

Our search of the PubMed, EMBASE and the Cochrane Reviews databases resulted in the identification of seven eligible studies in pregnancy, nine in pediatric patients and 13 in people using CSII. Records were assessed to be ineligible and thereby excluded from the systematic review and meta-analysis for numerous reasons, including the study not being a RCT (observational studies, letters, case reports or review articles were excluded); ineligible population; in vitro or animal studies; study dealt with one of the RAIAs in mixture formulations; outcomes of interest were not reported; PK/PD studies in which basal insulins were the focus of the study; study primarily addressing stability in pumps; health-economics studies without efficacy or safety outcomes; paper written in a language other than English; duplicate record; or study not applicable to this review for other reasons. A flow diagram showing the number of retrieved, excluded and included records is shown in Fig. 1. Prior to submission of this manuscript (August 2017), PubMed and the Cochrane Reviews were searched as previously described and no additional studies that would have been provisionally eligible were identified.

\section{Pregnancy}

Characteristics of the seven eligible studies in pregnancy (two in pre-gestational T1D [13-15] and four in GDM [16-19], with two reporting different outcomes from the same population

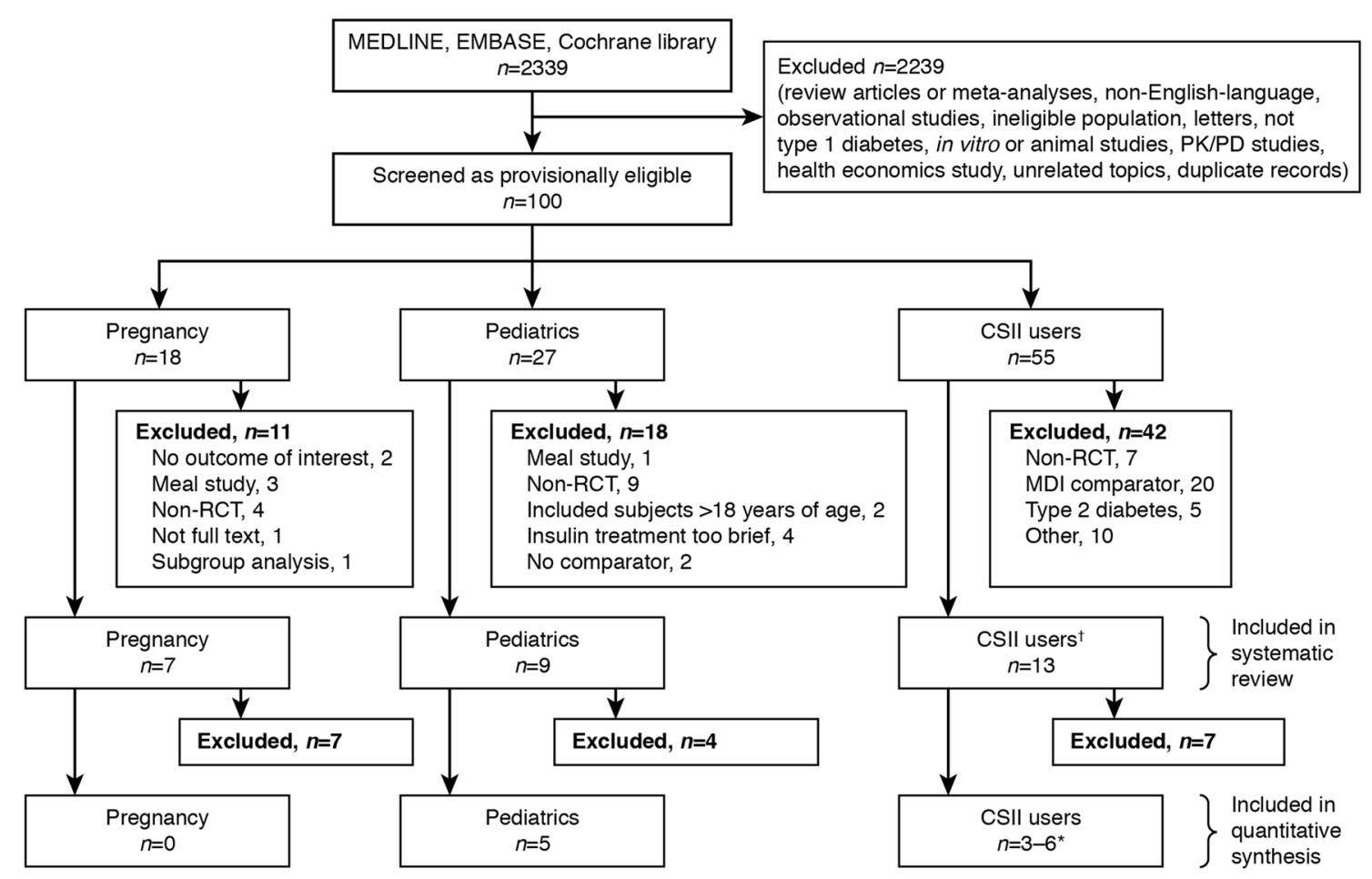

Fig. 1 Flow diagram showing the number of retrieved, excluded and included records. The dagger $(\dagger)$ indicates that the continuous subcutaneous insulin infusion (CSII) group included two pediatric CSII studies. The asterisk $\left({ }^{*}\right)$ indicates that in the CSII meta-analyses, the number of studies included varied depending on the outcome assessed. MDI Multiple daily injections, $P D$ pharmacodynamics, $P K$ pharmacokinetics, $R C T$ randomized controlled trial 


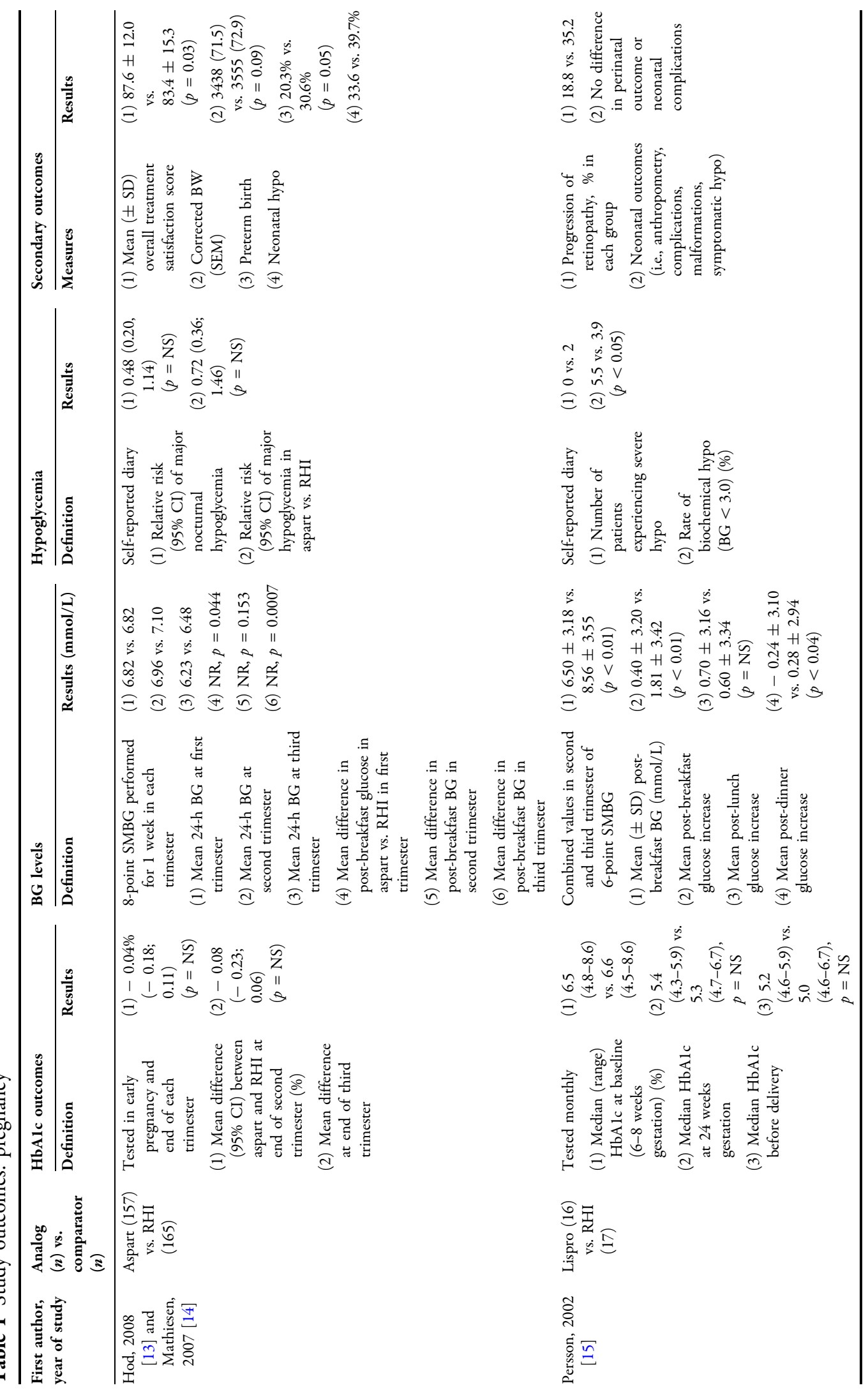




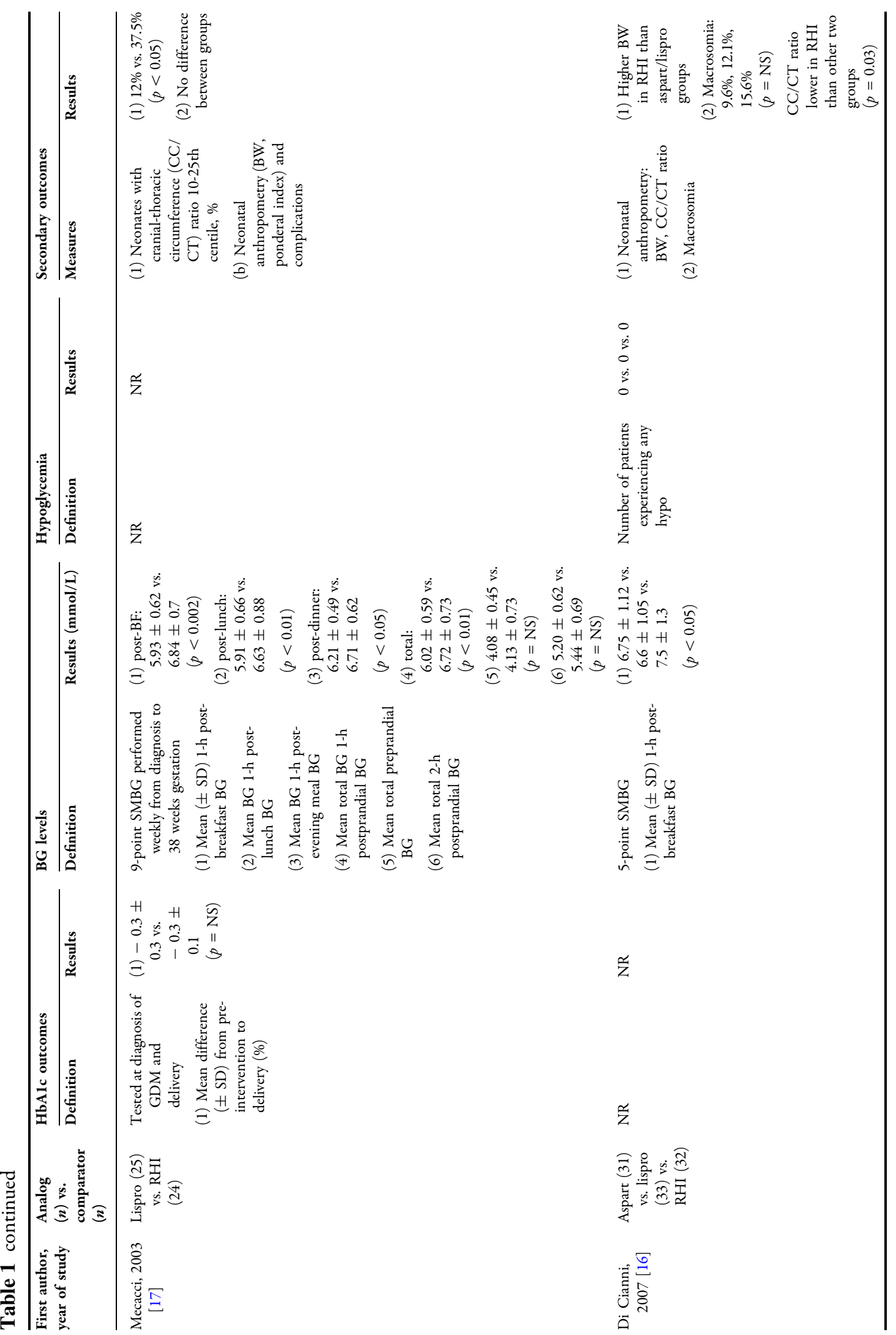




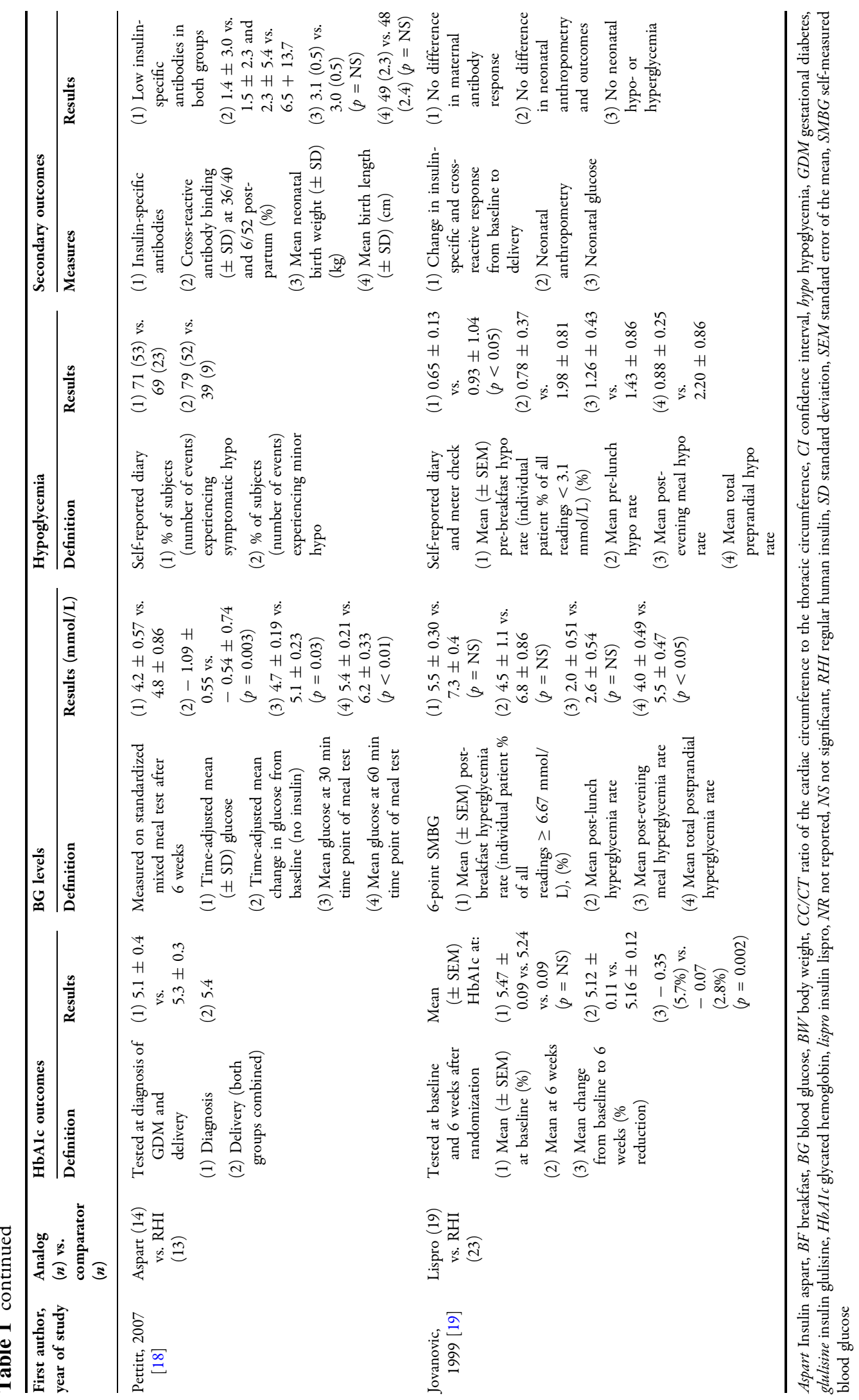


and therefore described in a single row $[13,14])$, are summarized in ESM Table S2, and the results of those studies are shown in Table 1. Most (4/6 trials) involved $<50$ participants. Study quality assessment is shown in ESM Table S3. Three studies were graded as -, two were graded as + and one was graded as ++ .

\section{Women with Pre-Existing T1D}

Persson et al. compared treatment with insulin lispro with RHI treatment in a group of 33 pregnant women with T1D and found that the BG level was significantly lower after breakfast (but not after other meals) with insulin lispro $(0.40 \pm 3.20$ vs. $1.81 \pm 3.42 \mathrm{mmol} / \mathrm{L} ; p<0.01)$ [15] (Table 1). The 95\% confidence interval (CI) was not significantly different between treatments, either at 24 weeks gestation or before delivery. The incidence of severe hypoglycemia was low (zero and two episodes for insulin lispro and RHI, respectively) and there were no differences in perinatal outcomes or neonatal complications.

The largest trial was an international, parallel-group trial enrolling 322 women with T1D who at enrollment were pregnant for $\leq 10$ weeks or planning to become pregnant. Women were randomized to either insulin aspart or RHI, both in combination with neutral protamine Hagedorn insulin as the basal insulin [14]. HbA1c levels were comparable in the two groups at the end of the second and third trimesters (treatment difference, insulin aspart-RHI: $-0.04 \%$ [95\% CI $-0.18 ; 0.11]$, $-0.4 \mathrm{mmol} / \mathrm{mol}[95 \% \mathrm{CI}-2.0 ; 1.2] ;$ and $-0.08 \%$ [95\% CI - 0.23; 0.06], - $0.9 \mathrm{mmol} /-$ mol [95\% CI - 2.5; 0.7], respectively). Mean plasma glucose levels at $90 \mathrm{~min}$ post-breakfast were significantly lower in those women receiving insulin aspart arm than in those receiving RHI $(p=0.044$ and $p=0.001$ for end of first and third trimesters, respectively). The mean PPG increment across all meals was lower for the insulin aspart arm than for the RHI arm at the end of the first and third trimesters (estimated treatment difference: -0.75 [95\% CI $-1.25 ;-0.25$ ], $p=0.003$ and -0.40 [95\% CI $-0.80 ;-0.01], p=0.044$, respectively). The risk of major hypoglycemic events was numerically lower, but not significantly different, for insulin aspart (rate ratio 0.72 [95\% CI 0.36; 1.46]).

In a publication reporting additional data on pregnancy outcomes by Mathiesen et al. [14], Hod et al. [13] indicated that preterm delivery occurred in 20.3 and $30.6 \%$ of pregnancies in women receiving insulin aspart and RHI, respectively ( $p=0.053)$. Other secondary publications from these trials indicated that there were 137 and 131 live births, 14 and 21 fetal losses, and six and nine congenital malformations in these groups of women on insulin aspart and RHI, respectively. Furthermore, maternal and cord blood antibody levels for both RHI and insulin aspart remained low for both treatments and were similar at 36 weeks gestation for the 97 women who participated in the substudy [20]. In a secondary analysis of data from the same trial, Lloyd et al. reported that these benefits were attained without increasing the cost of treatment compared to RHI [21].

\section{Women with GDM}

The characteristics of four RCTs using RAIAs in GDM are summarized in ESM Table S2 [16-19]. The results indicate that insulin lispro was at least as effective as RHI and sometimes demonstrated improved glycemic control (ESM Table S2) $[16,17,19]$. Insulin aspart was associated with significantly lower post-meal BG compared with RHI $[16,18]$. In the single trial involving a head-to-head comparison of insulin aspart and insulin lispro, mean 1-h post-breakfast BG was similar for the two products $(6.75 \pm 1.12$ vs. $6.6 \pm 1.05 \mathrm{mmol} / \mathrm{L}$, respectively) [16].

In Mecacci et al. [17], hypoglycemia was not reported and, in another trial, there were no hypoglycemic events reported for insulin aspart, insulin lispro or RHI [16]. In a study of women $(n=27)$ using insulin aspart or RHI, the reported percentage of participants experiencing symptomatic hypoglycemic events was similar for both treatments (71 vs. 69\%), but more participants using insulin aspart reported minor hypoglycemia (79 vs. 39\%) [18]. In the latter case, this was largely due to two participants being prone to hypoglycemia. Neonatal 
outcomes (weight, length, physical exam) were good for both insulin aspart and RHI.

\section{Meta-Analysis}

The pregnancy studies were deemed to be too heterogeneous or to lack relevant information for meta-analysis of either efficacy or safety outcomes for any of the three RAIAs.

\section{Children and Adolescents}

There were nine eligible studies involving pediatric patients with T1D [22-30]. The characteristics of these studies are presented in ESM Table S4 and the results are shown in Table 2. Three trials compared insulin aspart with RHI $[22,23,28]$, five compared insulin lispro with RHI [24-27, 30] and one compared insulin lispro with insulin glulisine [29]. Most (5/9; $55.5 \%)$ trials involved $<50$ participants. Study quality assessment is shown in ESM Table S5. Four studies were graded as -, two were graded as + and three were graded as ++ . Trials using RAIAs in CSII in children are discussed in the section "Patients Treated with CSII".

Overall, glycemic control (either HbA1c or PPG) with insulin lispro or insulin aspart was equivalent to or better than that with RHI. This was also true with respect to incidence of hypoglycemic episodes or other adverse events. There were no head-to-head trials comparing all three RAIAs in pediatric participants. However, a large $(n=572)$, open-label, parallel-group, non-inferiority trial compared insulin glulisine with insulin lispro [29]. Insulin glulisine was demonstrated to be non-inferior to insulin lispro (treatment difference in HbA1c: $-0.06 \%$ [95\% CI - 0.24; 0.12]; - 0.7 [95\% CI - 2.6; $1.33] \mathrm{mmol} / \mathrm{mol})$. More children achieved American Diabetes Association (ADA) agespecific HbA1c targets (at the time of the study: $<6$ years, HbA1c $>7.5$ to $\%<8.5 \%[>58$ to $<69 \mathrm{mmol} / \mathrm{mol}] ; 6-12$ years, $\mathrm{HbA} 1 \mathrm{c}<8.0 \%$ $[<64 \mathrm{mmol} / \mathrm{mol}] ; 13-17$ years, HbA1c $<7.5 \%$ $[<58 \mathrm{mmol} / \mathrm{mol}]$; currently, the ADA recommends HbA1c $<7.5 \%$ [ $<58 \mathrm{mmol} / \mathrm{mol}]$ across all pediatric age groups [1]) with insulin glulisine than with insulin lispro (overall population: 38.4 vs. $32.0 \%$ for insulin glulisine and insulin lispro, respectively; $p=0.039$ ). The frequencies of hypoglycemic events and other adverse events were similar.

\section{Meta-Analysis}

Data on glycemic control were deemed to be too heterogeneous or to lack relevant information for meta-analysis, but the data on severe hypoglycemic outcomes were able to be combined from five studies (Fig. 2a). Overall, the number of severe hypoglycemic events was low (total of 14), and a random-effects model using generic inverse variance showed no difference in risk of severe hypoglycemia with insulin analog treatment, risk difference $0(95 \% \mathrm{CI}-0.01 ; 0.01)$. Funnel plots suggested that there was no publication bias (data not shown).

\section{Patients Treated with CSII}

The largest number of eligible studies $(n=13)$ was identified for people using CSII [31-43], of which two were carried out in pediatric populations [42, 43] (ESM Table S6). The results are presented in Table 3, and the study quality assessment is shown in ESM Table S7. Two studies were graded as -, three were graded as + and seven were graded as ++ . One of the studies consisted of two substudies, one of which was graded as + , and the second was graded as ++ due to the double-blind component.

Eight studies compared an RAIA with RHI and all involved insulin lispro [32, 34-38, 41], with one being a pediatric trial [42]. All were crossover trials of 1-4 months' duration. All indicated that insulin lispro was associated with improved glycemic control (HbA1c) and an incidence of hypoglycemic events that was similar to or lower than RHI.

Three studies involved head-to-head comparisons of insulin lispro versus insulin aspart $[33,39,43]$, with an additional trial also comparing RHI [31]. The largest of the three trials was a 16-week, open-label RCT in 298 subjects with T1D aged 4-18 years [43] (ESM Table S6). At 16 weeks, the HbA1c in subjects receiving insulin aspart was deemed to be non-inferior to the $\mathrm{HbA} 1 \mathrm{c}$ in those receiving insulin lispro, and 


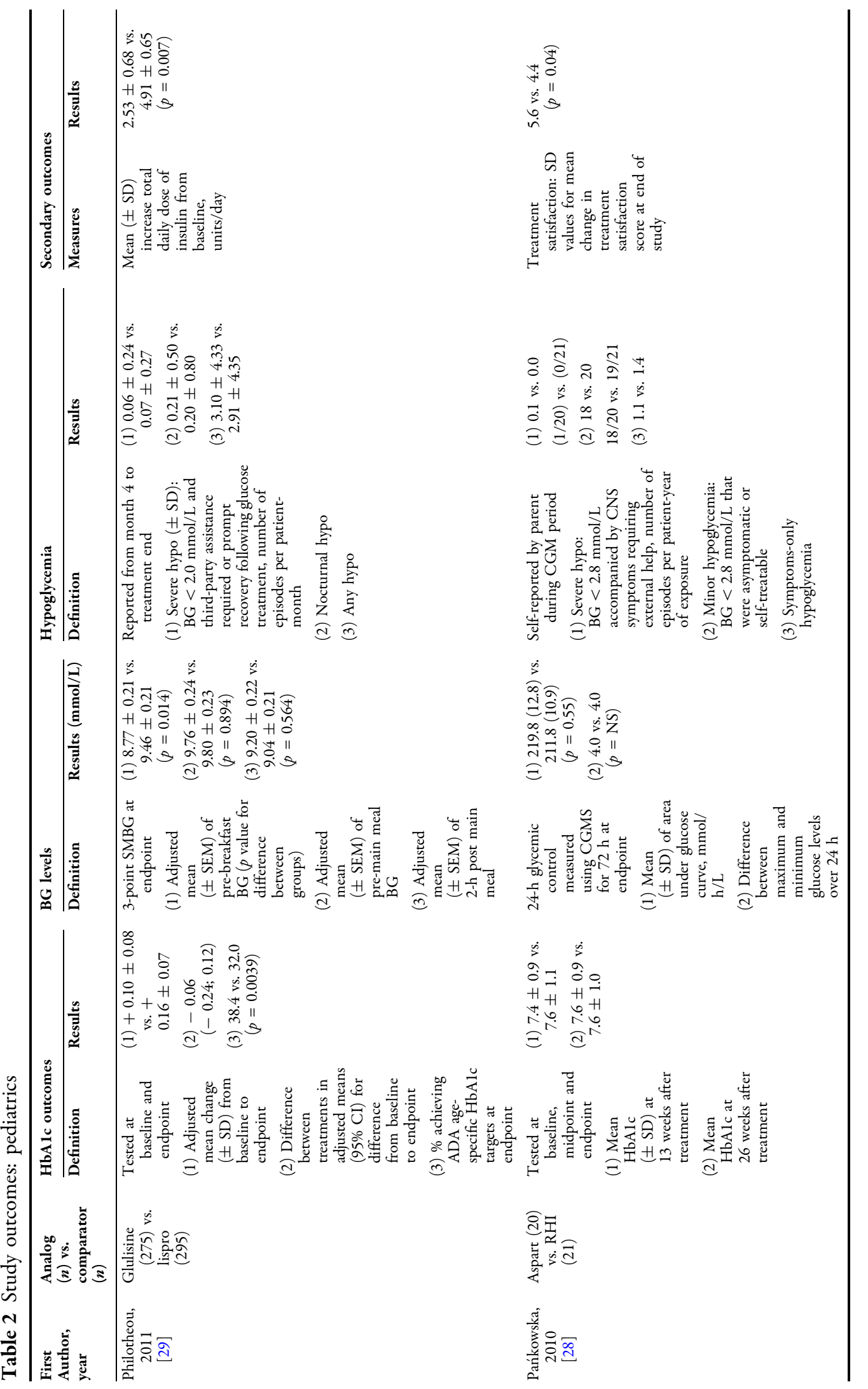




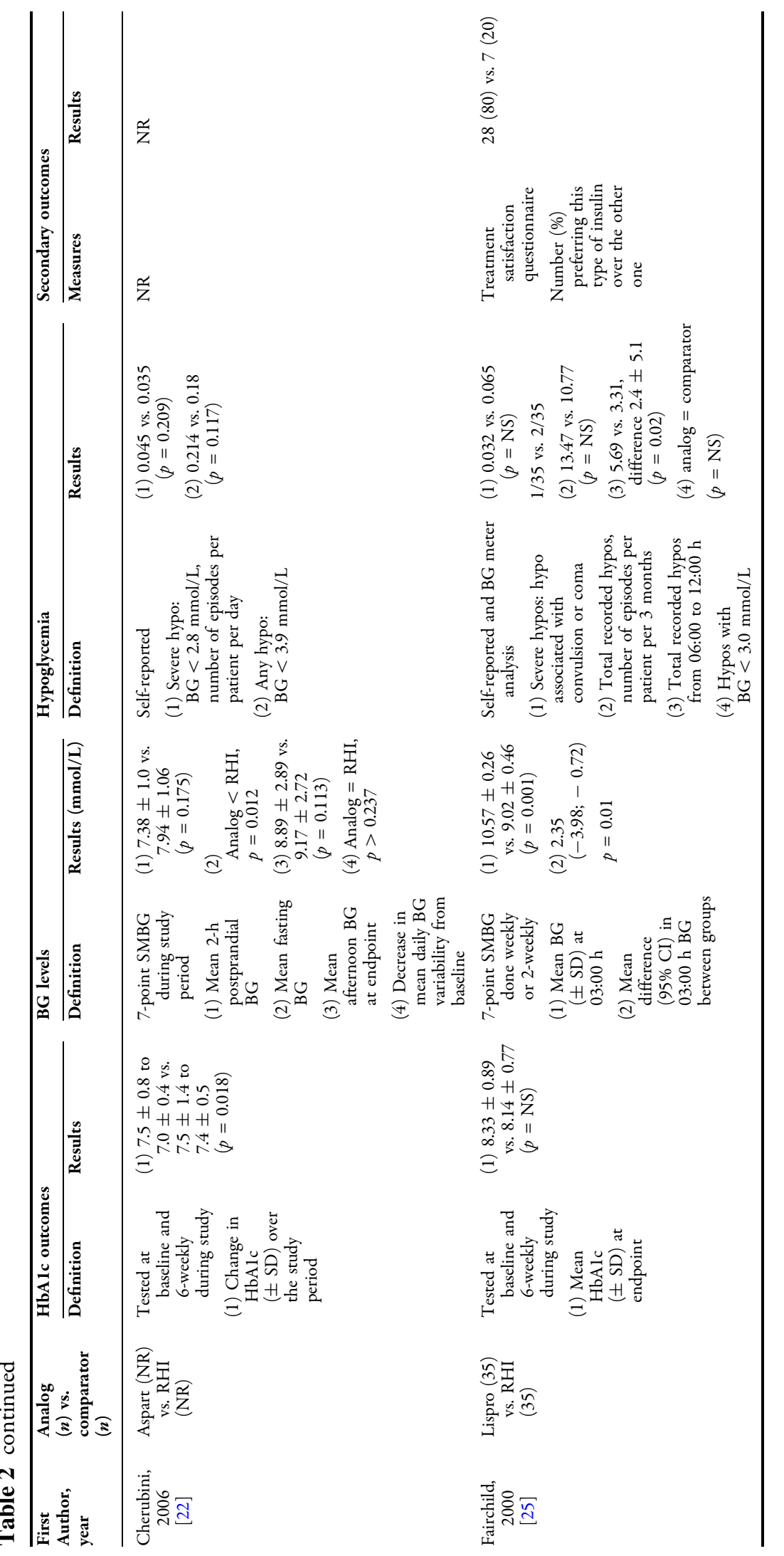




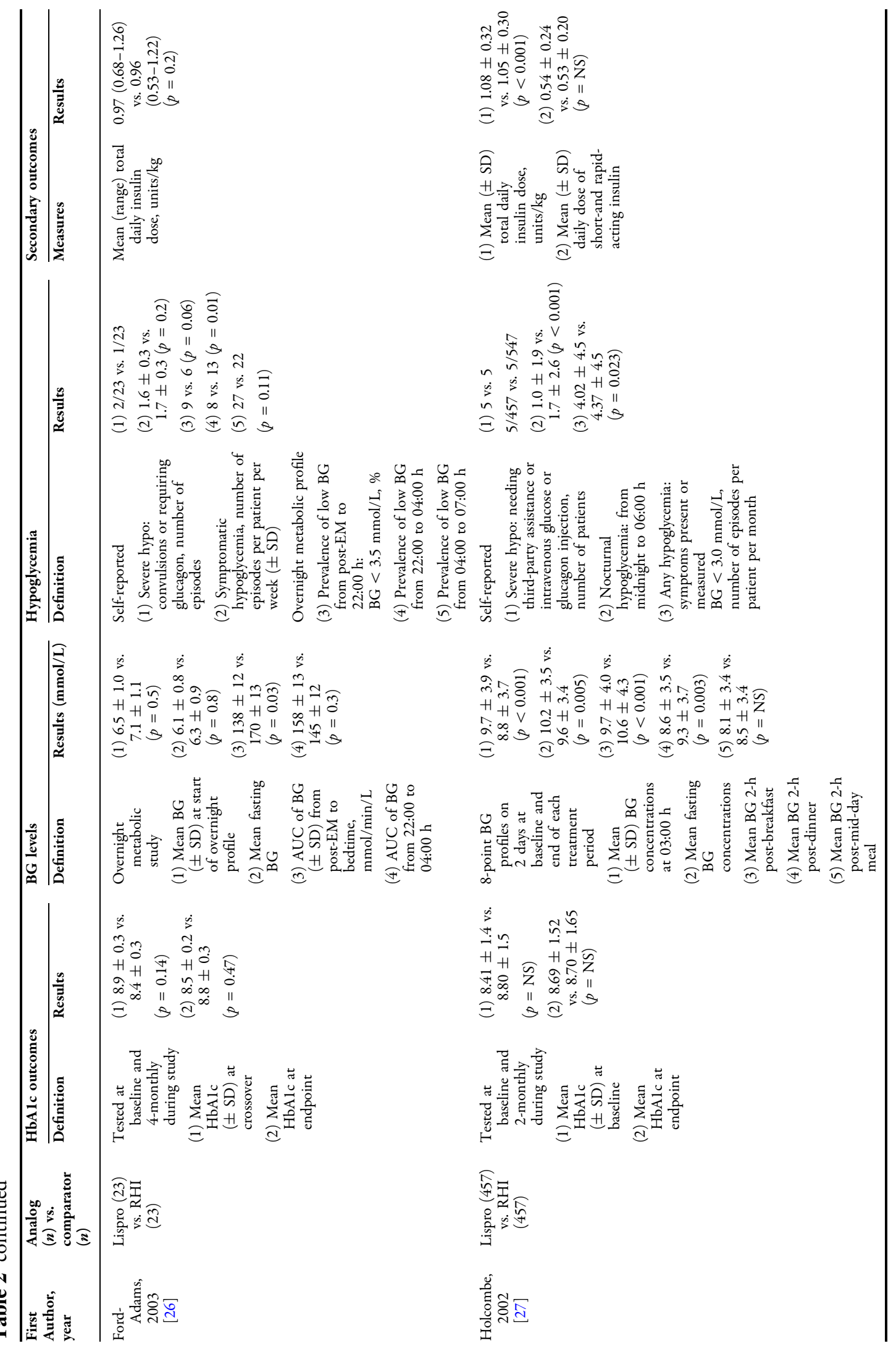




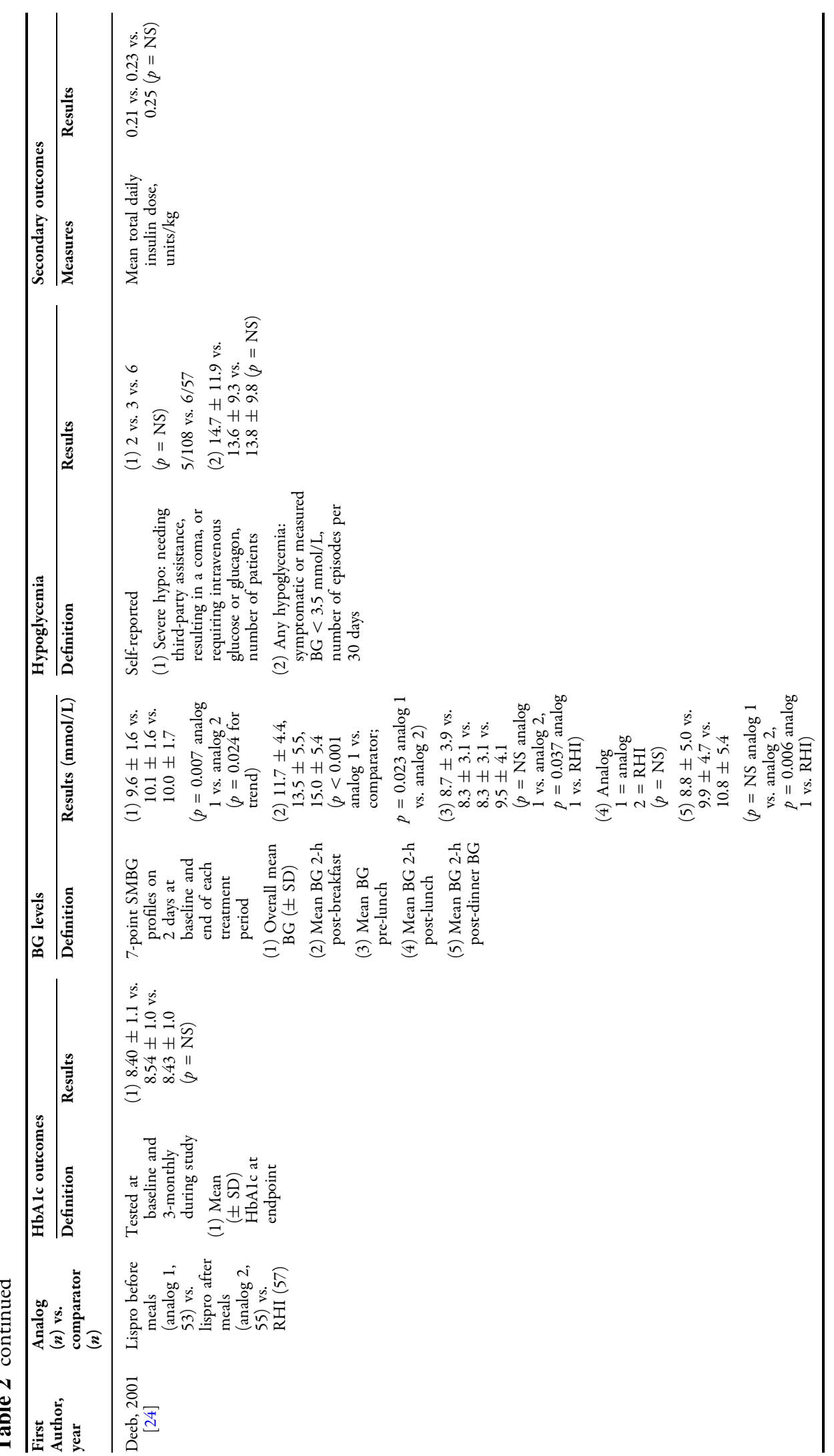




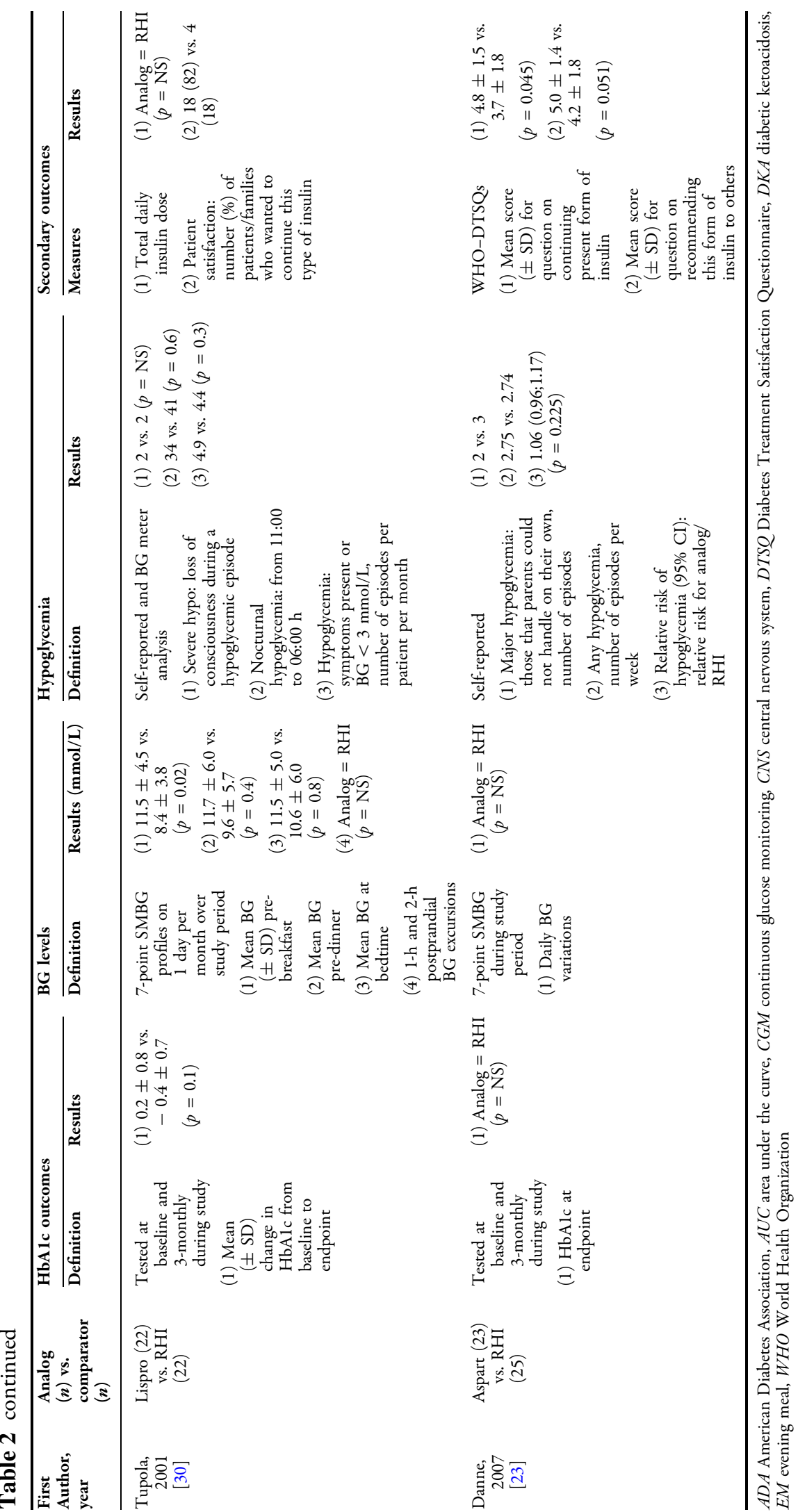




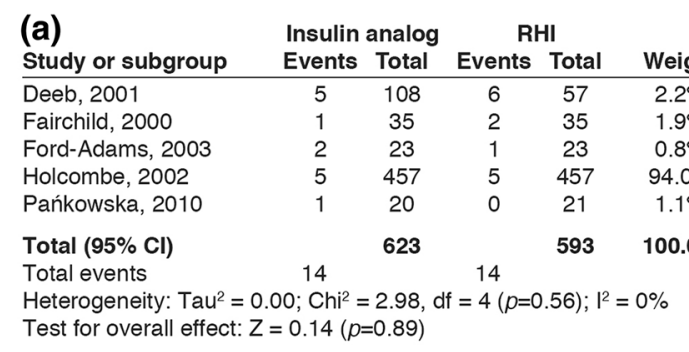

\section{(b)} \begin{tabular}{lcccccccc} 
Study or subgroup & Mean & SD & Total & Mean & SD & Total & Weight & IV, random, 95\% C \\
\hline Melki, 1998 & 7.7 & 0.17 & 38 & 7.75 & 0.21 & 38 & $36.2 \%$ & $-0.05(-0.14 ; 0.04)$
\end{tabular} $\begin{array}{lllllllll}\text { Renner, } 1999 & 7.2 & 1.7 & 113 & 7.8 & 2.1 & 113 & 30.4 \% & -0.60(-1.10 ;-0.10)\end{array}$

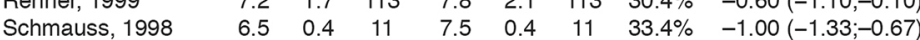
Total $(95 \% \mathrm{Cl}) \quad 162 \quad 162 \quad 100.0 \% \quad-0.53(-1.21 ; 0.15)$ Heterogeneity: $\mathrm{Tau}^{2}=0.33 ; \mathrm{Chi}^{2}=32.73, \mathrm{df}=2(p<0.00001) ; \mathrm{I}^{2}=94 \%$ Test for overall effect: $Z=1.54(p=0.12)$

Risk difference Risk difference

IV, random, $95 \% \mathrm{Cl}$ $-0.06(-0.15 ; 0.03)$ $-0.03(-0.12 ; 0.07)$ $0.04(-0.10 ; 0.19)$ $0.00(-0.01 ; 0.01)$ $0.05(-0.08 ; 0.18)$ $-0.00(-0.01 ; 0.01)$

CI
IV, random, $95 \% \mathrm{CI}$ \begin{tabular}{l|l}
\multicolumn{2}{l}{ IV, random, 95\% CI } \\
\hline
\end{tabular}

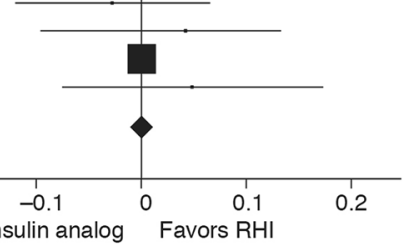

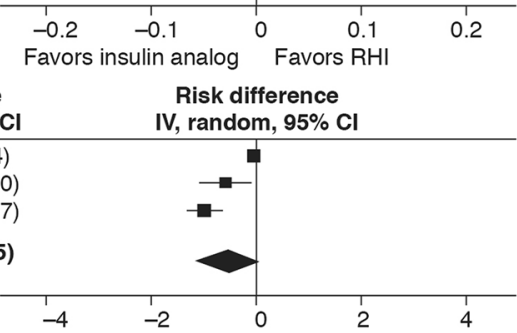

Favors insulin analog Favors $\mathrm{RHI}$

(c) Insulin analog $\quad \mathrm{RHI}$

Risk difference Study or subgroup Mean SD Total Mean SD Total Weight IV, random, $95 \% \mathrm{CI}$ \begin{tabular}{lllllllll}
\hline Guerci, 1999 & 9.43 & 1.39 & 10 & 10.49 & 2.05 & 10 & $0.3 \%$ & $-1.06(-2.60 ; 0.48)$
\end{tabular}

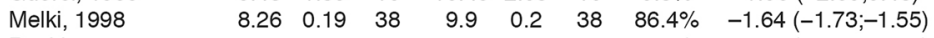
$\begin{array}{lllllllll}\text { Raskin, } 2001 & 9.64 & 4.1 & 58 & 12.53 & 4.64 & 58 & 0.3 \% & -2.89(-4.48 ;-1.30)\end{array}$

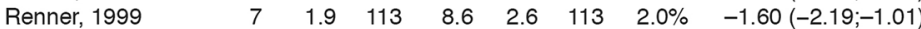

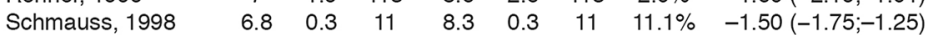

Total $(95 \% \mathrm{Cl}) \quad 230 \quad 230 \quad 100.0 \% \quad-1.63(-1.71 ;-1.54)$ Heterogeneity: $\mathrm{Tau}^{2}=0.00 ; \mathrm{Chi}^{2}=4.01, \mathrm{df}=4(p=0.40) ; \mathrm{I}^{2}=0 \%$ Test for overall effect: $Z=38.06(p<0.00001)$

(d) Insulin analog $\quad$ RHI $\mathrm{RHI}$ $0 \%$ Study or subgroup Events Total Events Total \begin{tabular}{cc} 
Weight & $\begin{array}{c}\text { Risk difference } \\
\text { IV, random, 95\% CI }\end{array}$ \\
\hline $36.0 \%$ & $-0.02(-0.06 ; 0.03)$ \\
$19.8 \%$ & $-0.02(-0.08 ; 0.04)$ \\
$4.5 \%$ & $-0.03(-0.16 ; 0.10)$ \\
$13.8 \%$ & $0.02(-0.06 ; 0.09)$ \\
$2.9 \%$ & $0.00(-0.16 ; 0.16)$ \\
$3.9 \%$ & $0.00(-0.14 ; 0.14)$ \\
$19.1 \%$ & $0.00(-0.06 ; 0.06)$ \\
$100.0 \%$ & $-0.01(-0.04 ; 0.02)$
\end{tabular} \begin{tabular}{ccccc}
\hline-4 & -2 & 0 & 2 & 4 \\
Favors insulin analog & Favors & RHI &
\end{tabular} Bode, 2002 (a) Bode, 2002 (b) Melki, 1998 Raskin, 2001 Schmaus, 1998 Tubiana-Rufi, 2004 Zinmann, 1997

Total $(95 \% \mathrm{Cl})$ $\begin{array}{lll}\text { Total events } & 8 & 10 \\ \text { Heterogeneity: } \mathrm{Tau}^{2}=0.00 ; & \mathrm{Chi}^{2}=0.84, \mathrm{df}=6(p=0.99) ;\left.\right|^{2}=0 \%\end{array}$ Test for overall effect: $Z=0.59(p=0.56)$

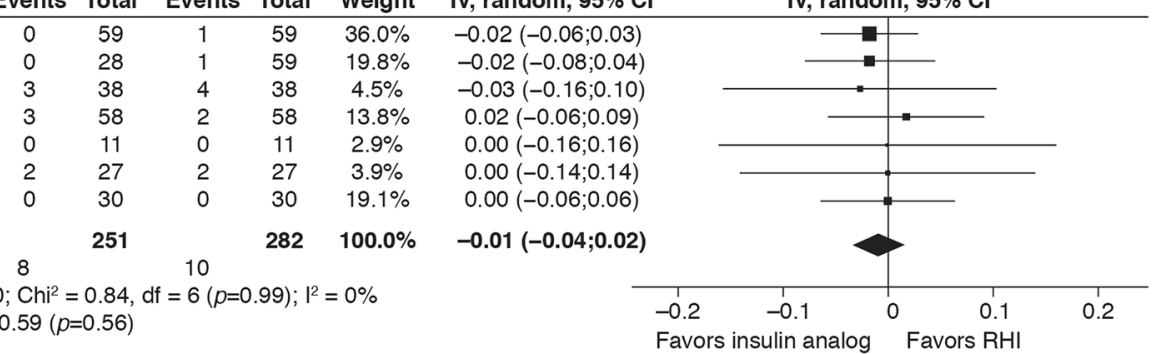

\section{(e)} Insulin analog RHI Risk difference Risk difference
IV, random, $95 \% \mathrm{Cl}$

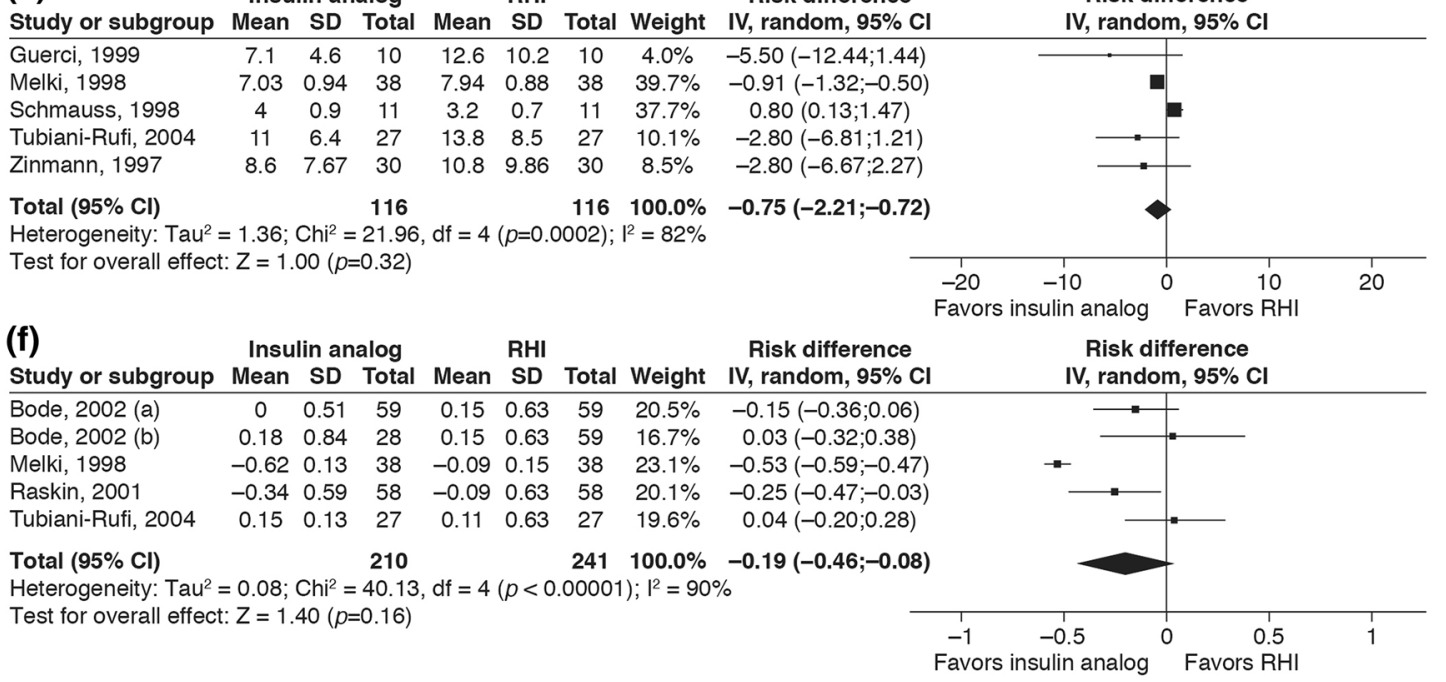


4Fig. 2 Meta-analyses of key outcomes. a Forest plot showing the difference in risk of severe hypoglycemic episodes with insulin analog treatment compared to regular human insulin $(R H I)$ in a pediatric population. b Forest plot showing the difference in the mean fasting blood glucose level with insulin analog treatment compared to RHI treatment in the CSII sub-review. c Forest plot showing the difference in mean postprandial blood glucose (BG) level with insulin analog treatment compared to RHI treatment in the CSII sub-review. d Forest plot showing the difference in risk of severe hypoglycemic episodes with insulin analog treatment compared to RHI treatment in the CSII sub-review. e Forest plot showing the mean difference in the rate of any hypoglycemic episodes with insulin analog treatment compared to RHI treatment in the CSII sub-review. f Forest plot showing the difference in glycated hemogloblin (HbAlc) with insulin analog treatment (lispro or aspart) compared to RHI in the CSII sub-review.

Squares and diamonds represent the difference in HbAlc after intervention with the two treatments for each study (horizontal lines are $95 \% \mathrm{CI}$ ) and for all the studies combined, respectively. The $I^{2}$ value refers to the statistical heterogeneity for the pooled analysis. A random-effects model using generic inverse variance showed a mean difference in HbAlc of $-0.19 \%$ (95\% CI -0.46 ; 0.08 ); $-2.1(95 \% \mathrm{CI}-5.0 ; 0.9) \mathrm{mmol} / \mathrm{mol}$ with insulin analog compared to RHI at the end of the treatment period. The squares and the diamond in $\mathbf{a}, \mathbf{d}$, e represent the difference in risk for each study (horizontal lines represent 95\% CI) and for all studies combined, respectively. The squares and the diamond in $\mathbf{b}, \mathbf{c}$ represent the difference in the glucose levels between the two treatment arms for each study (horizontal lines are $95 \% \mathrm{CI}$ ) and for all the studies combined, respectively. The results of these meta-analyses are the mean of post-breakfast BG measurements only. In a and d 'Events' refers to the number of patients experiencing any such episode during the treatment period as a proportion of total number of patients in that treatment group. 'Rate' refers to mean ( $\pm S D$ ) of any episodes of hypoglycemia per 30 days in all the patients in the respective treatment group. In f 'Bode, 2002 (a)' [31] refers to the observed difference in $\mathrm{HbAlc}$ between the subgroup of insulin lispro vs. RHI, and 'Bode, 2002 (b)' [31] refers to the subgroup on insulin aspart vs. RHI; the three remaining studies compare lispro vs. RHI. The ' $I$ ', value refers to the statistical heterogeneity for this pooled analysis. $C I$ confidence interval, $I V$ inverse variance, $S D$ standard deviation there were no significant differences in FBG or rates of hyper- and hypoglycemia. However, the daily insulin dose was significantly lower for groups on insulin aspart $(0.86 \pm 0.237$ vs. $0.94 \pm 0.233 \mathrm{U} / \mathrm{kg}$, for insulin aspart vs. insulin lispro, respectively; $p=0.018$ ) [43]. In two related, 24-week, randomized, crossover trials in adults with T1D, insulin lispro was assessed to be non-inferior to insulin aspart based on SMBG profiles averaged over days 1-6 of treatment, but not when day 6 values alone were compared [39]. In a randomized, parallel-group trial in 146 adults with T1D, mean change from baseline was not significantly different for participants treated with insulin lispro, insulin aspart or RHI for 16 weeks [31]. Rates of hypoglycemia were also similar among treatments.

One RCT compared all three RAIAs in adults [40]. This was a crossover trial with three 13-week periods that was designed to test the superiority of insulin glulisine for unexplained hyperglycemia and/or infusion-set occlusion. It failed to show superiority of insulin glulisine on the primary outcome, but revealed that the monthly rate of unexplained hyperglycemic episodes and/or perceived catheter-set occlusion was significantly higher in insulin glulisine-treated patients than in those receiving the two other analogs [40]. Furthermore, insulin glulisine was associated with a higher frequency of symptomatic hypoglycemia, whereas HbA1c and 7-point SMBG were similar for all three insulin analogs [40].

\section{Meta-analysis}

Data on mean FBG and mean PPG for patients using CSII were sufficiently consistent to permit some meta-analysis, as were some of the hypoglycemic outcomes. Funnel plots suggested that there was no publication bias, although the number of studies in the meta-analysis with FBG outcomes was small (funnel plots not shown). Meta-analysis was performed for RAIAs versus RHI for FBG (three studies) (Fig. 2b), PPG (five studies) (Fig. 2c), severe hypoglycemic episodes (six studies) (Fig. 2d), any hypoglycemic episodes (five studies) (Fig. 2e) and HbA1c (four studies) (Fig. 2f). A random-effects model using generic inverse variance showed a mean difference in FBG of $-0.53 \mathrm{mmol} / \mathrm{L}$ 


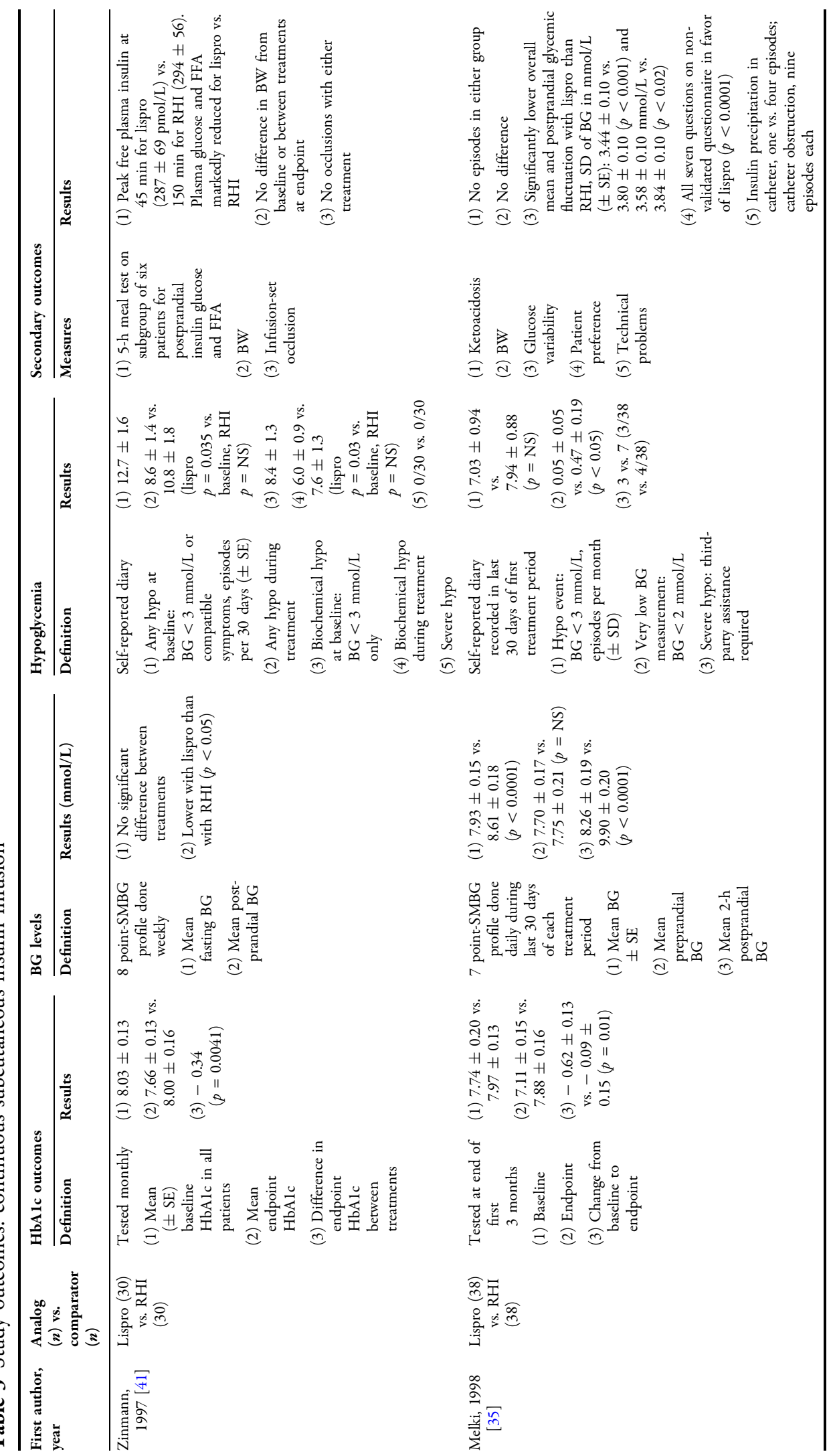




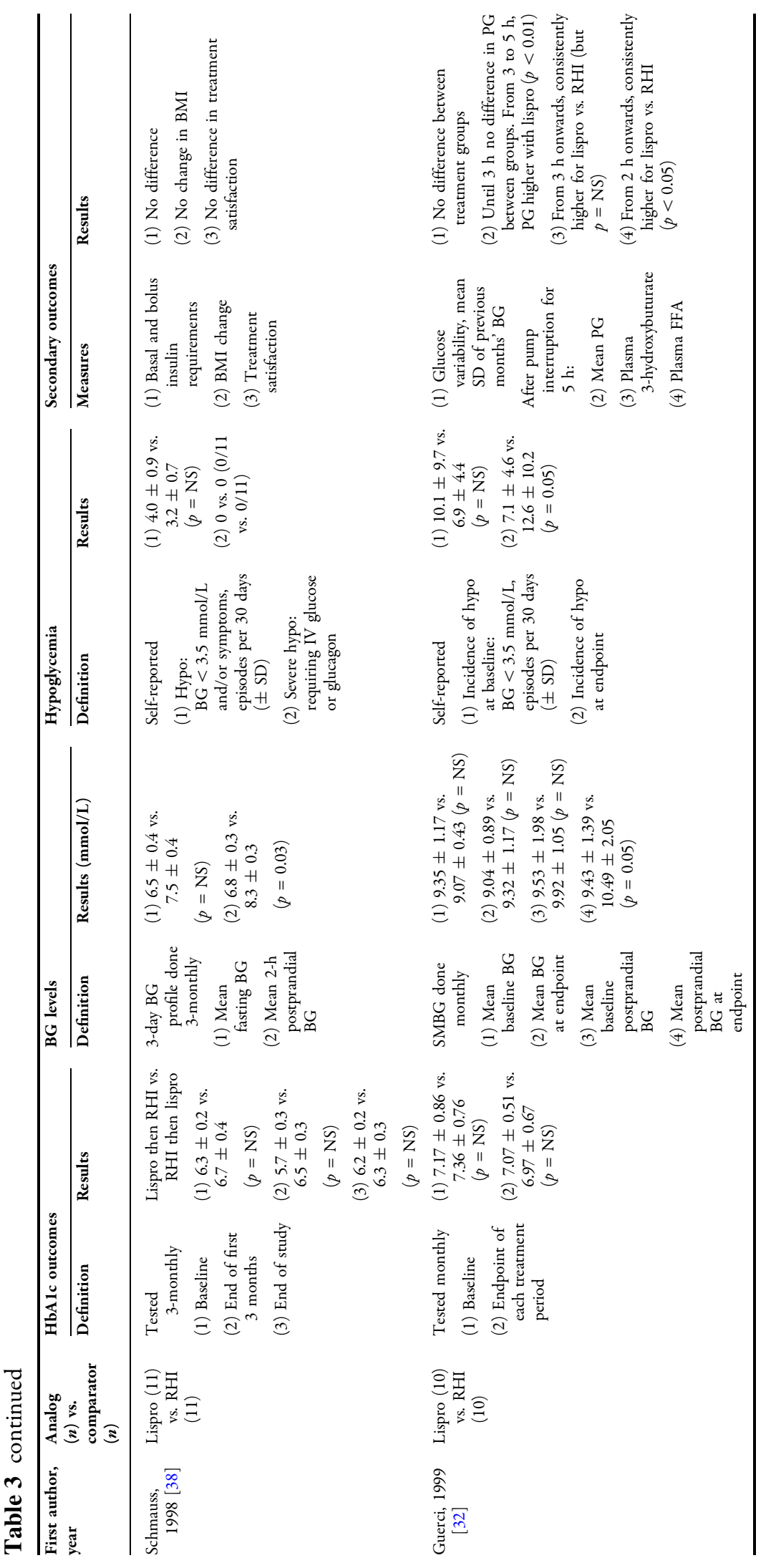




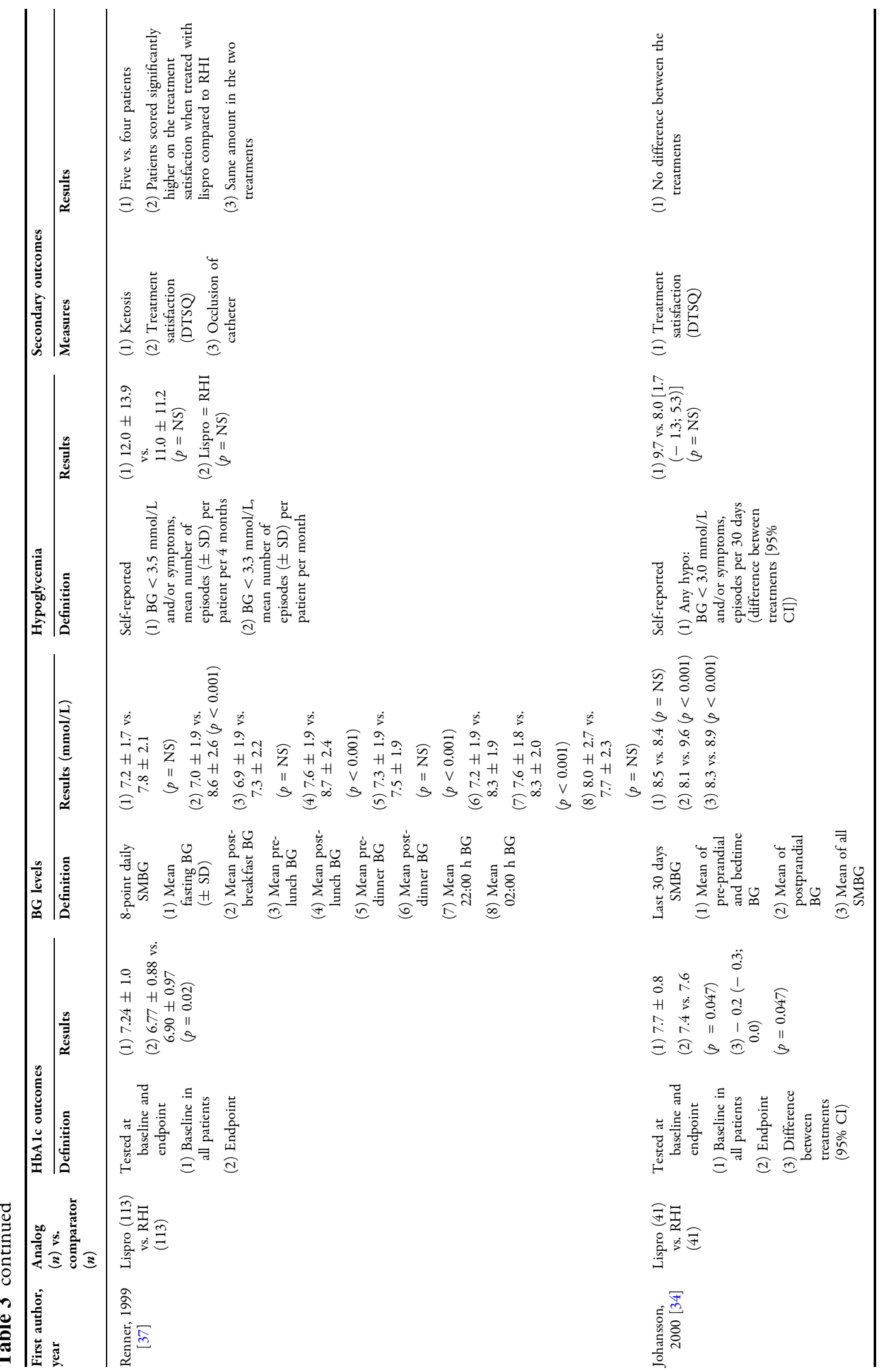




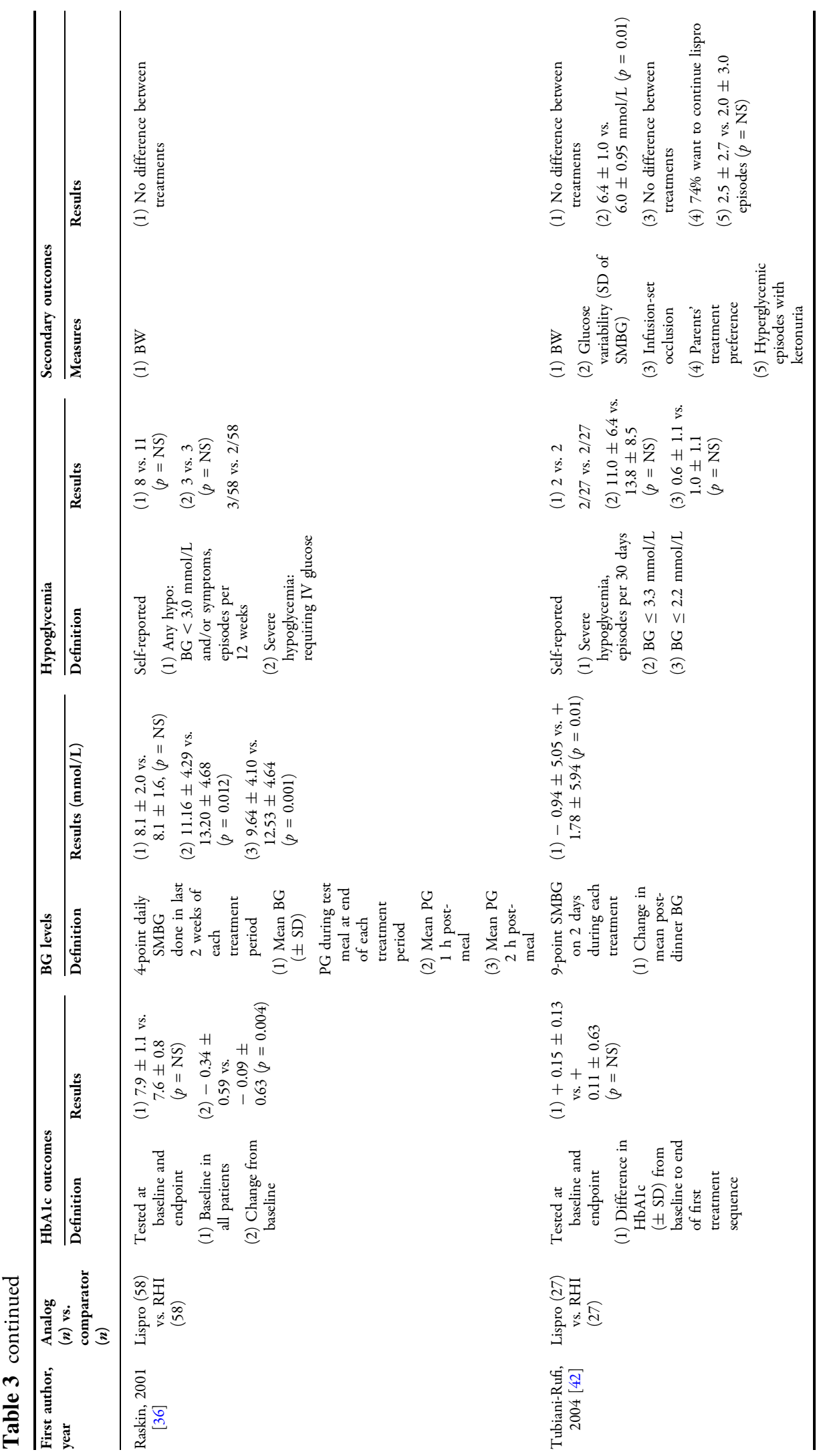




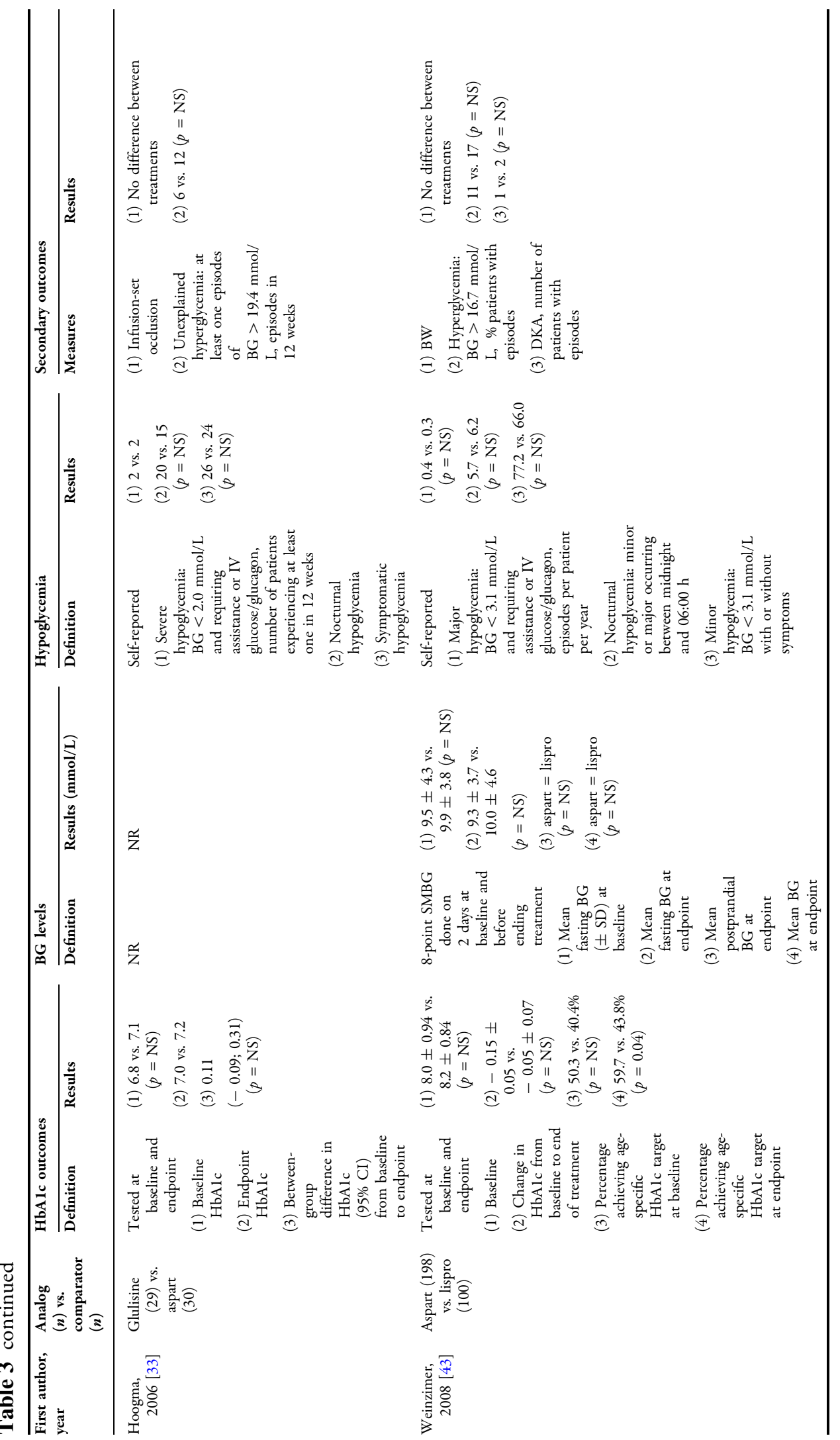




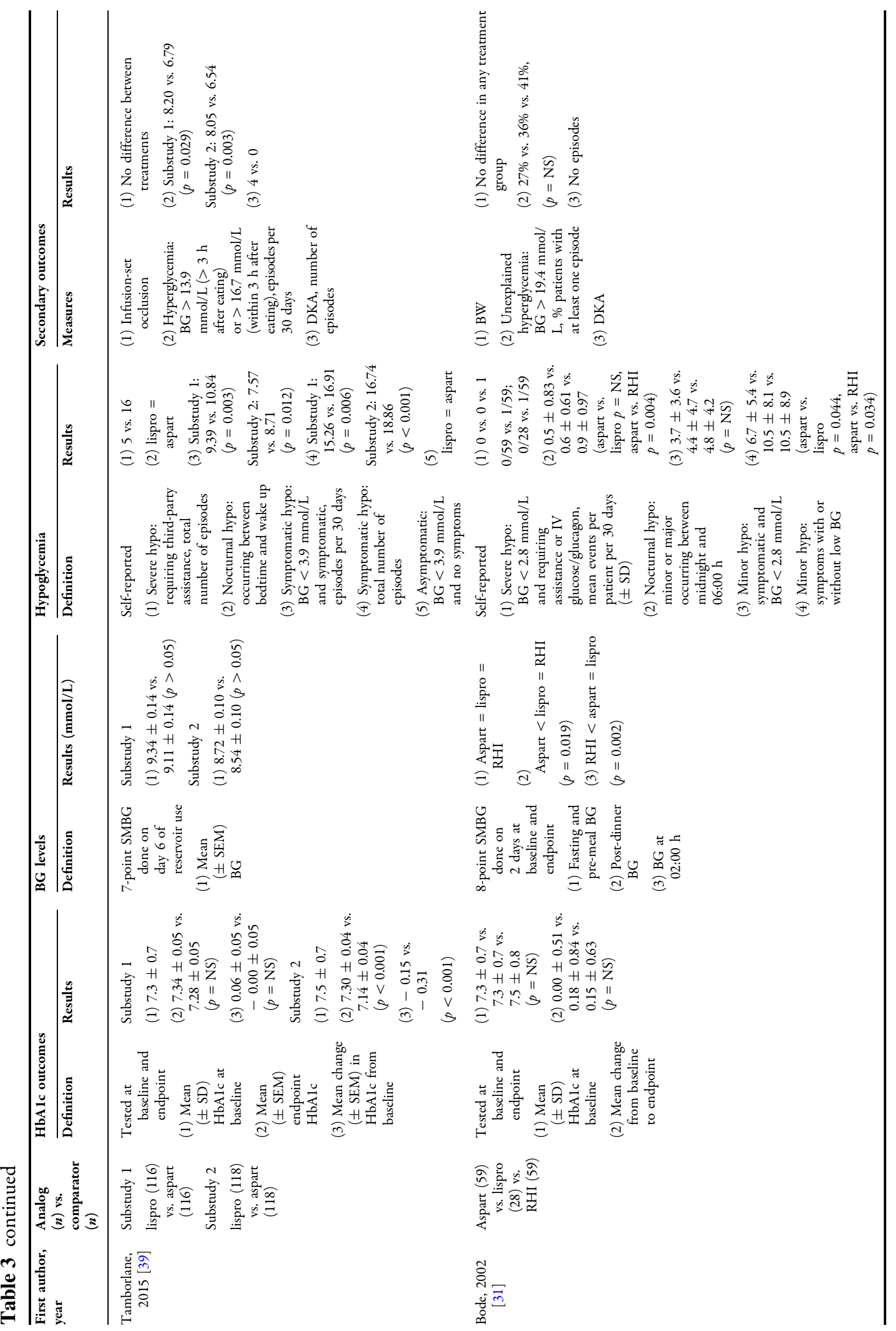




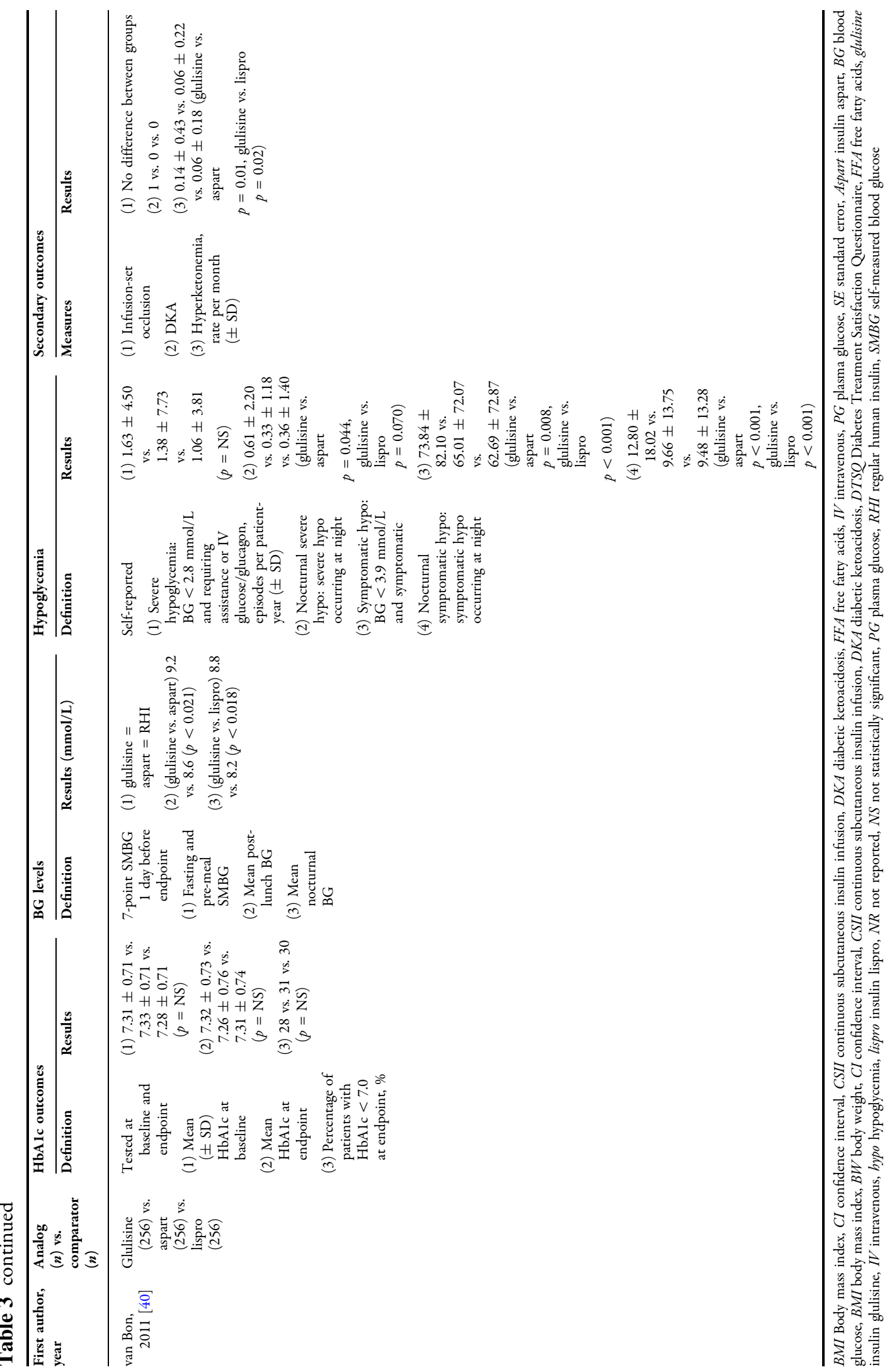


(95\% CI - 1.21; 0.15), a mean difference for PPG of $-1.63 \mathrm{mmol} / \mathrm{L}(95 \% \mathrm{CI}-1.71 ;-1.54)$, a risk difference for severe hypoglycemic episodes of $-0.01(95 \% \mathrm{CI}-0.04 ; 0.02)$ and a mean difference in rate of any hypoglycemic episode of $-0.75(95 \% \mathrm{CI}-2.21 ; 0.72)$. The mean difference in $\mathrm{HbA1c}$ was $-0.19 \%(95 \% \mathrm{CI}-0.46$; $0.08) ;-2.1 \mathrm{mmol} / \mathrm{mol}(95 \% \mathrm{CI}-5.0 ; 0.9)$ with RAIAs compared to RHI after 3 or 4 months of treatment.

\section{DISCUSSION}

This systematic review and meta-analysis summarizes the safety and efficacy of RAIAs in populations of patients who are either typically excluded from clinical trials (i.e. due to pregnancy) or require dedicated trials (i.e. children and adolescents, patients using CSII). Overall, for insulin lispro and insulin aspart, data across all three special populations indicate that their safety and efficacy are comparable with, and in some cases significantly better than, RHI. Data also suggest, from the more limited results available, similar characteristics for insulin glulisine.

There are no head-to-head RCTs individually comparing all three RAIAs with each other in the pediatric CSII setting. However, in 2009, the Institute for Quality and Efficiency in Health Care in Germany, acknowledging the limited amount of data at the time, concluded that there were no significant differences between RHI and any of the three RAIAs in terms of key efficacy and safety endpoints [44]. The UK National Institute for Health and Care Excellence (NICE) guidelines specifically indicate that RAIAs are preferred over RHI for use in CSII for pediatric patients [45].

Given the lack of any major safety concerns when the three RAIAs were studied individually, there is no a priori reason to suspect that headto-head trials would reveal any substantive differences in safety among them in special populations. However, without randomized comparative trials in these special populations, that conclusion remains speculative. Due to the limited number of studies and the heterogeneity of the outcome measures, only limited meta- analysis was possible, primarily in the CSII population. Those results indicate that RAIAs in CSII lower post-breakfast BG and possibly HbA1c to a greater extent than RHI, without an increased risk of hypoglycemia. Although many trials have been published using CSII versus multiple daily injections (MDI) in pediatric subjects, we did not review those here because it was impossible to separate the effects of the RAIA from those of the mode of treatment (CSII or MDI).

\section{CONCLUSIONS}

Rapid-acting insulin analogs appear to be safe and effective in these three special populations of people with T1D. However, additional trials would be helpful, and head-to-head trials would be necessary to detect any statistical differences among them, should they exist. The lack of clinically relevant differences in performance among the RAIAs make other factors, such as cost, availability and patient/provider preference, more important. Finally, studies have now been published indicating the PK advantages of a new formulation of insulin aspart in clinical development (faster aspart) over conventional insulin aspart [46], including in pediatric populations [47] and in those using CSII [48]. Studies addressing the performance of new fastacting insulin aspart versus insulin glulisine and insulin lispro in these special populations in a clinical setting would be advantageous.

\section{ACKNOWLEDGEMENTS}

Funding. The authors received no funding for data abstraction, meta-analysis and writing. This work was supported by Novo Nordisk A/S. Novo Nordisk A/S funded the writing and editing assistance as well as the article publication charge, and reviewed the manuscript for scientific accuracy. The authors determined which studies were eligible for the review and metaanalysis, performed the meta-analysis and made the decision to submit the manuscript for publication. 
Medical Writing and Editorial Assistance. The authors are grateful to Gary Patronek, Helen Marshall and Erin Slobodian, of Watermeadow Medical, an Ashfield company, part of UDG Healthcare plc, for writing and editing assistance in the development of this manuscript. Gary Patronek also performed the literature search and assisted with data abstraction. This assistance was funded by Novo Nordisk $\mathrm{A} / \mathrm{S}$, who also had a role in the review of the manuscript for scientific accuracy.

Authorship. All named authors meet the International Committee of Medical Journal Editors (ICMJE) criteria for authorship for this article, take responsibility for the integrity of the work as a whole, and have given their approval for this version to be published.

Disclosures. Kirsten Nørgaard serves as adviser to Medtronic, Abbott and Novo Nordisk, owns shares in Novo Nordisk, has received research grants from Roche and Novo Nordisk and has received fees for speaking from Medtronic, Roche, Rubin Medical, Sanofi, Novo Nordisk and Bayer. Ponnusamy Saravanan has received honoraria for serving on advisory boards and speaker fees for all three rapid-acting insulin analog-producing companies (Novo Nordisk, Sanofi and Lilly). Nithya Sukumar and Snorri B. Rafnsson declare they have no conflict of interest.

Compliance with Ethics Guidelines. This article is based on previously conducted studies, and does not involve any new studies of human or animal subjects performed by any of the authors.

Data Availability. Data used in the metaanalysis are included in Fig. 1.

Open Access. This article is distributed under the terms of the Creative Commons Attribution-NonCommercial 4.0 International License (http://creativecommons.org/licenses/ by-nc/4.0/), which permits any noncommercial use, distribution, and reproduction in any medium, provided you give appropriate credit to the original author(s) and the source, provide a link to the Creative Commons license, and indicate if changes were made.

\section{REFERENCES}

1. American Diabetes Association. Standards of medical care in diabetes-2017. Diabetes Care. 2017;40[Suppl 1]:S1-135.

2. Eli Lilly. Humalog prescribing information. www. accessdata.fda.gov/drugsatfda_docs/label/2013/020 563s115lbl.pdf; 2013. Accessed 29 Jan 2018.

3. Novo Nordisk. NovoLog prescribing information. www.accessdata.fda.gov/drugsatfda_docs/label/2015/ 020986s082lbl.pdf; 2015. Accessed 29 Jan 2018.

4. Sanofi Aventis. Apidra prescribing information. www.accessdata.fda.gov/drugsatfda_docs/label/2015/ 021629s030lbl.pdf; 2015. Accessed 29 Jan 2018.

5. Eli Lilly. Humalog product information. www.ema. europa.eu/ema/index.jsp?curl=pages/medicines/hum an/medicines/000088/human_med_000820.jsp\& mid=WC0b01ac058001d124; 2017. Accessed 29 Jan 2018.

6. Novo Nordisk. NovoRapid product information. www.ema.europa.eu/ema/index.jsp?curl=pages / medicines/human/medicines/000258/human_med_ 000935.jsp\&mid=WC0b01ac058001d124; 2017. Accessed 29 Jan 2018.

7. Sanofi Aventis. Apidra product information. www. ema.europa.eu/ema/index.jsp?curl=pages/medicines/ human/medicines/000557/human_med_000648.jsp\& mid=WCOb01ac058001d124; 2017. Accessed 29 Jan 2018.

8. Bohn B, Karges B, Vogel C, et al. 20 years of pediatric benchmarking in Germany and Austria: agedependent analysis of longitudinal follow-up in 63,967 children and adolescents with type 1 diabetes. PLoS One. 2016;11:e0160971.

9. Mooradian AD. Special considerations with insulin therapy in older adults with diabetes mellitus. Drugs Aging. 2011;28:429-38.

10. Kerr D, Wizemann E, Senstius J, Zacho M, AmpudiaBlasco FJ. Stability and performance of rapid-acting insulin analogs used for continuous subcutaneous insulin infusion: a systematic review. J Diabetes Sci Technol. 2013;7:1595-606.

11. Home PD. The pharmacokinetics and pharmacodynamics of rapid-acting insulin analogues and 
their clinical consequences. Diabetes Obes Metab. 2012;14:780-8.

12. Chiang JL, Kirkman MS, Laffel LM, Peters AL, Type 1 Diabetes Sourcebook Authors. Type 1 diabetes through the life span: a position statement of the American Diabetes Association. Diabetes Care. 2014;37:2034-54.

13. Hod M, Damm P, Kaaja R, et al. Fetal and perinatal outcomes in type 1 diabetes pregnancy: a randomized study comparing insulin aspart with human insulin in 322 subjects. Am J Obstet Gynecol. 2008;198(186):e1-7.

14. Mathiesen ER, Kinsley B, Amiel SA, et al. Maternal glycemic control and hypoglycemia in type 1 diabetic pregnancy: a randomized trial of insulin aspart versus human insulin in 322 pregnant women. Diabetes Care. 2007;30:771-6.

15. Persson B, Swahn ML, Hjertberg R, et al. Insulin lispro therapy in pregnancies complicated by type 1 diabetes mellitus. Diabetes Res Clin Pract. 2002;58:115-21.

16. Di Cianni G, Volpe L, Ghio A, et al. Maternal metabolic control and perinatal outcome in women with gestational diabetes mellitus treated with lispro or aspart insulin: comparison with regular insulin. Diabetes Care. 2007;30:e11.

17. Mecacci F, Carignani L, Cioni R, et al. Maternal metabolic control and perinatal outcome in women with gestational diabetes treated with regular or lispro insulin: comparison with non-diabetic pregnant women. Eur J Obstet Gynecol Reprod Biol. 2003;111:19-24.

18. Pettitt DJ, Ospina P, Howard C, Zisser H, Jovanovic L. Efficacy, safety and lack of immunogenicity of insulin aspart compared with regular human insulin for women with gestational diabetes mellitus. Diabet Med. 2007;24:1129-35.

19. Jovanovic L, Ilic S, Pettitt DJ, et al. Metabolic and immunologic effects of insulin lispro in gestational diabetes. Diabetes Care. 1999;22:1422-7.

20. McCance DR, Damm P, Mathiesen ER, et al. Evaluation of insulin antibodies and placental transfer of insulin aspart in pregnant women with type 1 diabetes mellitus. Diabetologia. 2008;51:2141-3.

21. Lloyd A, Townsend C, Munro V, Twena N, Nielsen S, Holman A. Cost-effectiveness of insulin aspart compared to human insulin in pregnant women with type 1 diabetes in the UK. Curr Med Res Opin. 2009;25:599-605.

22. Cherubini V, Iannilli A, Iafusco D, et al. Premeal insulin treatment during basal-bolus regimen in young children with type 1 diabetes. Diabetes Care. 2006;29:2311-2.

23. Danne $\mathrm{T}$, Råstam J, Odendahl $\mathrm{R}$, et al. Parental preference of prandial insulin aspart compared with preprandial human insulin in a basal-bolus scheme with NPH insulin in a 12-wk crossover study of preschool children with type 1 diabetes. Pediatr Diabetes. 2007;8:278-85.

24. Deeb LC, Holcombe JH, Brunelle R, et al. Insulin lispro lowers postprandial glucose in prepubertal children with diabetes. Pediatrics. 2001;108:1175-9.

25. Fairchild JM, Ambler GR, Genoud-Lawton CH, et al. Insulin lispro versus regular insulin in children with type 1 diabetes on twice daily insulin. Pediatr Diabetes. 2000;1:135-41.

26. Ford-Adams ME, Murphy NP, Moore EJ, et al. Insulin lispro: a potential role in preventing nocturnal hypoglycaemia in young children with diabetes mellitus. Diabet Med. 2003;20:656-60.

27. Holcombe JH, Zalani S, Arora VK, Mast CJ, Lispro in Adolescents Study Group. Comparison of insulin lispro with regular human insulin for the treatment of type 1 diabetes in adolescents. Clin Ther. 2002;24:629-38.

28. Pańkowska E, Nazim J, Szalecki M, Urban M. Equal metabolic control but superior caregiver treatment satisfaction with insulin aspart in preschool children. Diabetes Technol Ther. 2010;12:413-8.

29. Philotheou A, Arslanian S, Blatniczky L, Peterkova V, Souhami E, Danne T. Comparable efficacy and safety of insulin glulisine and insulin lispro when given as part of a basal-bolus insulin regimen in a 26-week trial in pediatric patients with type 1 diabetes. Diabetes Technol Ther. 2011;13:327-34.

30. Tupola S, Komulainen J, Jääskeläinen J, Sipilä I. Post-prandial insulin lispro vs. human regular insulin in prepubertal children with type 1 diabetes mellitus. Diabet Med. 2001;18:654-8.

31. Bode B, Weinstein R, Bell D, et al. Comparison of insulin aspart with buffered regular insulin and insulin lispro in continuous subcutaneous insulin infusion: a randomized study in type 1 diabetes. Diabetes Care. 2002;25:439-44.

32. Guerci B, Meyer L, Sallé A, et al. Comparison of metabolic deterioration between insulin analog and regular insulin after a 5-hour interruption of a continuous subcutaneous insulin infusion in type 1 diabetic patients. J Clin Endocrinol Metab. 1999;84:2673-8. 
33. Hoogma RP, Schumicki D. Safety of insulin glulisine when given by continuous subcutaneous infusion using an external pump in patients with type 1 diabetes. Horm Metab Res. 2006;38:429-33.

34. Johansson UB, Adamson UC, Lins PE, Wredling RA. Improved blood glucose variability, HbA1c insuman Infusat and less insulin requirement in IDDM patients using insulin lispro in CSII. The Swedish Multicenter Lispro Insulin Study. Diabetes Metab. 2000;26:192-6.

35. Melki V, Renard E, Lassmann-Vague V, et al. Improvement of HbA1c and blood glucose stability in IDDM patients treated with lispro insulin analog in external pumps. Diabetes Care. 1998;21:977-82.

36. Raskin P, Holcombe JH, Tamborlane WV, et al. A comparison of insulin lispro and buffered regular human insulin administered via continuous subcutaneous insulin infusion pump. J Diabetes Complications. 2001;15:295-300.

37. Renner R, Pfützner A, Trautmann M, Harzer O, Sauter K, Landgraf R. Use of insulin lispro in continuous subcutaneous insulin infusion treatment. Results of a multicenter trial. German HumalogCSII Study Group. Diabetes Care. 1999;22:784-8.

38. Schmauss S, König A, Landgraf R. Human insulin analogue [LYS(B28), PRO(B29)]: the ideal pump insulin? Diabet Med. 1998;15:247-9.

39. Tamborlane WV, Renard E, Wadwa RP, et al. Glycemic control after 6 days of insulin pump reservoir use in type 1 diabetes: results of double-blind and open-label cross-over trials of insulin lispro and insulin aspart. J Diabetes. 2015;7:270-8.

40. van Bon AC, Bode BW, Sert-Langeron C, DeVries $\mathrm{JH}$, Charpentier G. Insulin glulisine compared to insulin aspart and to insulin lispro administered by continuous subcutaneous insulin infusion in patients with type 1 diabetes: a randomized controlled trial. Diabetes Technol Ther. 2011;13:607-14.

41. Zinman B, Tildesley H, Chiasson JL, Tsui E, Strack T. Insulin lispro in CSII: results of a double-blind crossover study. Diabetes 1997;46:440-3. Erratum. Diabetes. 1997;46:1239.
42. Tubiana-Rufi N, Coutant R, Bloch J, et al. Special management of insulin lispro in continuous subcutaneous insulin infusion in young diabetic children: a randomized cross-over study. Horm Res. 2004;62:265-71.

43. Weinzimer SA, Ternand C, Howard C, Chang CT, Becker DJ. Laffel LM; Insulin Aspart Pediatric Pump Study Group. A randomized trial comparing continuous subcutaneous insulin infusion of insulin aspart versus insulin lispro in children and adolescents with type 1 diabetes. Diabetes Care. 2008;31:210-5.

44. Institute for Quality and Efficiency in Health Care: executive summaries. Rapid-acting insulin analogues in children and adolescents with diabetes mellitus type 1-follow-up commission: executive summary of final report A08-01, version 1.0. 2005-2009. Cologne, Germany: Institute for Quality and Efficiency in Health Care (IQWiG); 2009.

45. UK National Institute for Health and Care Excellence. Diabetes (type 1 and type 2) in children and young people: diagnosis and management. NICE guideline [NG18]. 2015. www.nice.org.uk/ guidance/ng18 (Accessed 29 Jan 2018).

46. Heise T, Pieber TR, Danne T, Erichsen L, Haahr H. A pooled analysis of clinical pharmacology trials investigating the pharmacokinetic and pharmacodynamic characteristics of fast-acting insulin aspart in adults with type 1 diabetes. Clin Pharmacokinet. 2017;56:551-9.

47. Fath M, Danne T, Biester T, Erichsen L, Kordonouri $\mathrm{O}$, Haahr H. Faster-acting insulin aspart provides faster onset and greater early exposure vs. insulin aspart in children and adolescents with type 1 diabetes mellitus. Pediatr Diabetes. 2017;18:903-10.

48. Heise T, Zijlstra E, Nosek L, Rikte T, Haahr H. Pharmacological properties of faster-acting insulin aspart vs. insulin aspart in patients with type 1 diabetes receiving continuous subcutaneous insulin infusion: a randomized, double-blind, crossover trial. Diabetes Obes Metab. 2017;19:208-15. 